\title{
AMÉRICA Y EL ESPACIO TRANSMAGALLÁNICO, SIGLO XVI
}

RICARDO PADRÓN

\section{RESUMEN}

Se examinan varios momentos en la historia de la representación del estrecho de Magallanes y el Mar del Sur a lo largo del siglo XVI, que sirven para ilustrar algunas de las maneras en que la imaginación geopolítica de la temprana modernidad española respondió a la invención de América como un continente separado de Asia. En esta serie de visiones imperiales de lo que se puede llamar el espacio transmagallánico, se lucha contra la tendencia prevalente de aislar al Nuevo Mundo, de considerarlo como un lugar aparte, construyendo una versión de las Indias Occidentales como una geografía transpacífica.

PALABRAS CLAVE: estrecho de Magallanes, Mar del Sur, América, Nuevo Mundo, invención, cartografía, mapas, geopolítica.

\section{AMERICA AND TRANSMAGELLANIC SPACE, XVITH CENTURY}

\section{ABSTRACT}

This essay examines various moments in the history of the sixteenth-century representation of the Strait of Magellan and the South Sea that illustrate some of the ways that the early modern Spanish geopolitical imagination resisted the ongoing invention of America as a continent separate from Asia. In this series of visions of what we can call transmagellanic space, the Spanish geopolitical imagination struggles against the prevailing tendency to isolate the New World, to map it as a place apart, by constructing a transpacific version of the geography of the West Indies.

KEY WORDS: Strait of Magellan, South Sea, America, New World, Invention, cartography, maps, geopolitics.

a Universidad de Virginia, EE.UU. Department of Spanish, Italian and Portuguese, University of Virginia PO Box 400777, Charlottesville, VA 22902 USA. \ padron@virginia.edu 
Pues entrad, cosmógrafos, por el estrecho que digo, e id a buscar tierra a tierra el cabo de Labrador a la parte del Norte, exige Gonzalo Fernández de Oviedo en su Historia general y natural de las Indias, haciendo referencia al estrecho de Magallanes, y marcándolo como un punto de inflexión crucial en la geografía del Nuevo Mundo, o más bien, en el desarrollo del conocimiento geográfico sobre el Nuevo Mundo, algo todavía bajo construcción en la época ${ }^{1}$. Sabemos que Oviedo tenía acceso a una carta náutica por el cosmógrafo español Alonso de Chaves, posiblemente una versión de la que se encuentra ahora en el Herzog August Bibliotheck (HAB) en Wolfenbüttel, Alemania, la cual tiene un aire de familia inconfundible con los otros planisferios producidos durante esta época por la Casa de la Contratación y que ahora se encuentran salpicados por varias bibliotecas europeas ${ }^{2}$ (Fig. 1). La carta del HAB, al igual que aquellas otras cartas sevillanas, traza la costa atlántica desde Labrador hasta el estrecho de Magallanes en su totalidad, pero deja grandes partes de la costa pacífica en blanco, específicamente los trechos desde el estrecho de Magallanes hasta la costa del Ecuador moderno y luego desde Centroamérica hacia el norte. A pesar de estas lagunas en el conocimiento de la geografía del Nuevo Mundo, Oviedo no dudaba que la exploración de la costa pacífica del Nuevo Mundo acabaría mostrando que el continente entero tomaba la forma de una isla enorme físicamente separada de Asia. Tanto en el pasaje citado como en la descripción más completa que hace de la costa pacífica del Nuevo Mundo al principio de la tercera parte de su obra, insiste que se puede pasar por el estrecho de Magallanes, girar hacia el norte y seguir la costa hasta encontrarse

1 Fernández de Oviedo, 1535. La historia general de las Indias. Recuperado de http://hdl.handle.net/2027/ ucm.5323537519, fol. 117v; Fernández de Oviedo y Valdés, 1851. Historia general y natural de las Indias. Edición de J. Amador de los Ríos. Imprenta de la Real Academia de la Historia, Madrid, Google Books, vol. 1. p. 464.

2 Para examinar el mapa de Chaves en alta resolución, véase http://diglib.hab.de/mss/104a-aug-2f/start.htm. Acceso el 10 de julio del 2019. Todos los planisferios existentes de la Casa de la Contratación se encuentran reproducidos en Martín Merás, 1992. Cartografía marítima hispánica: La de nuevo en Labrador ${ }^{3}$. De esta manera, incorpora al estrecho de Magallanes en una trayectoria imaginativa y discursiva destinada a identificar al Nuevo Mundo como un continente separado de Asia y sin precedentes en el conocimiento grecolatino o medieval.

Existe una larga tradición historiográfica que interpreta la geografía de los planisferios de la Casa de la Contratación de la misma manera que Oviedo, identificando en sus trazos fragmentarios de las costas americanas contribuciones cruciales a la invención de los territorios nuevamente descubiertos en el Mar Océano como la cuarta parte del mundo. Desde el siglo XIX, a más tardar, aquella tradición se ha apoyado en una determinada práctica editorial, la de publicar la parte de los planisferios ibéricos donde figura el Nuevo Mundo, sin reproducir la carta en su totalidad. Esto es lo que hizo Friedrich Kunstmann al armar una de las primeras colecciones impresas de mapas manuscritos de América, publicada en 1859, la misma práctica seguida por los editores del sitio web de la $\mathrm{HAB}$, donde se encuentra una versión digitalizada de la hoja de la carta de Chaves donde figura el Nuevo Mundo, pero no la otra hoja, donde se encuentra el resto del hemisferio que la corona castellana reclamaba como suyo un hemisferio que incluía las islas Molucas y la China ${ }^{4}$. Dentro de la tradición historiográfica que se preocupa por la aparición de la imagen de América en la conciencia geográfica de Occidente, aquellos sitios orientales salen fuera del marco, particularmente después de que la expedición de Magallanes mostrara que la distancia entre el Nuevo Mundo y la Especiería era más larga de la que se había imaginado antes de zarpar su flota, y que por lo tanto la tierra firme de las Indias

imagen de América. Lunwerg, Madrid. Martín Merás es la responsable de haber identificado la fecha y autoría del mapa de Chaves (pp. 100-101). El estudio más reciente sobre la cartografía de la Casa de la Contratación es el de Sánchez, 2013. La espada, la cruz y el Padrón: Soberanía, fe y representación cartográfica en el mundo ibérico bajo la Monarquía Hispánica, 1503-1598. Consejo Superior de Investigaciones Científicas, Madrid.

3 Fernández de Oviedo y Valdés, 1851, op. cit., vol 4. pag 16.

4 Kunstmann, 1859. Atlas zur Entdeckungsgeschichte Amerikas. Asher in Comm., Munich. 


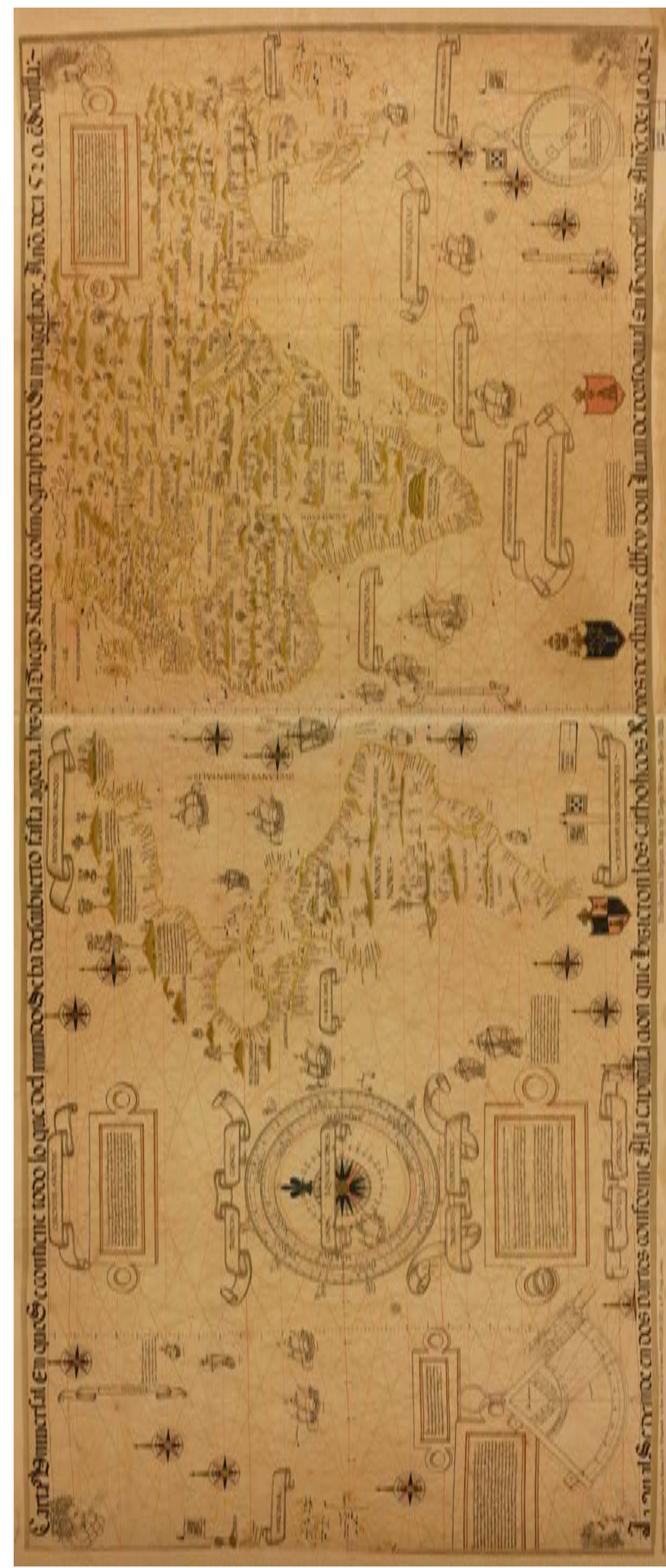

españolas no podía formar parte del continente asiático. Según esta tradición, el estrecho de Magallanes es un lugar netamente americano, $\mathrm{y}$ su penetración un episodio en el largo proceso de la invención de América.

En nuestros días, sin embargo, el paradigma historiográfico de la invención de América se está poniendo en tela de juicio. Nicolás Wey Gómez y otros estudiosos interesados en el problema de la tropicalidad nos han señalado la importancia que tenían para el pensamiento tardío medieval y renacentista otros esquemas metageográficos, la teoría climática en particular ${ }^{5}$. Incluso otros han llamado nuestra atención a la tendencia de "confundir" las dos Indias, occidentales y orientales, que se puede identificar en la escritura, la cartografía y el coleccionismo de la primera modernidad. Elizabeth Horodowich y Alexander Nagel, en particular, han logrado hacer visible un "pensamiento amerasiático" según el cual los conceptos de "América" o el "Nuevo Mundo" no eran incompatibles con una noción abarcadora de "las Indias", que no distinguía de manera tajante entre aquel continente y Asia, entre Oriente

5 Safier, 2014. The Tenacious Travels of the Torrid Zone and the Global Dimensions of Geographical Knowledge in the Eighteenth Century. Journal of Early Modern History, 18(1-2), pp. 141172; Wey Gómez, 2008. The Tropics of Empire: Why Columbus Sailed South to the Indies. MIT Press, Cambridge, Mass.; Wey Gómez, 2013. Memorias de la zona tórrida: El naturalismo clásico y la "tropicalidad" americana en el Sumario de la natural historia de las Indias de Gonzalo Fernández de Oviedo (1526). Revista de Indias, 73(259), pp. 609-632.

Fig. 1. Se abre un espacio amplio entre el Nuevo Mundo y las Maluccas en este planisferio de la Casa de la Contratación en Sevilla. Copia de Diogo Ribiero. Carta universal en que se contiene todo lo que del mundo se ha descubierto fasta agora (Sevilla, 1529). Biblioteca del Congreso, Washington, DC. El original se encuentra en la Biblioteca del Vaticano. 
y Occidente $^{6}$. Nosotros coincidimos con ellos en reconocer la vigencia extraordinaria de conceptos geográficos que parecen resistir la idea de que América formaba un lugar aparte, pero proponemos que la relación entre los conceptos de América y de Amerasia se tiene que entender como una pugna dialéctica. A lo largo del siglo XVI, cada vez que se inventa América como tal en algún lugar para un determinado público, se la deshace en otro lugar para otro público. Aquella pugna se puede entender como una alternancia entre dos posibles respuestas a la misma pregunta: ¿a dónde nos lleva el estrecho de Magallanes? Para cada Oviedo que insiste en que aquella ruta conduce al litoral pacífico del continente americano y que sirve para desarrollar el conocimiento de América como un continente aparte, podemos identificar una figura opuesta para el cual el Estrecho sigue siendo lo que había sido para Magallanes, el camino hacia aquellas partes del mapa que se suelen olvidar o aun borrar cuando se trata de América, unas Indias transpacíficas en las cuales el Nuevo Mundo es algo diferente de Asia, pero que sin embargo no se queda aislado.

\section{UN PASAJE AMERICANO}

La idea originalmente propuesta por Martin Waldseemüller y Mathias Ringmann en 1507, que el Nuevo Mundo representaba una enorme isla de estatus continental físicamente separada de Asia que debería llamarse América en honor a Americo Vespucio, tardó casi medio siglo en conseguir aprobación general. Según una pila de historiadores establecidos, como son Gaylord Bourne, Francisco Morales Padrón, Samuel Eliot Morison, J. H. Parry y Oskar Spate y otros, uno de los momentos claves del proceso fue el descubrimiento por Fernando de Magallanes que la distancia entre el Nuevo Mundo y las Molucas era mucho más grande de lo que se había esperado. Este descubrimiento, según ellos,

6 Horodowich y Nagel, 2019. Amerasia: European Reflections of an Emergent World, 1492-ca. 1700. Journal of Early Modern History, 23, 257-295.

7 Bourne, 1904. Spain in America, 1450-1580. Harper \& Brothers, New York y London, p. 132; Morales Padrón, 1963. Historia del descubrimiento y Conquista de América. Editorial Nacional, Madrid, p. 168; Morison, 1971. The European Discovery of America. Oxford University Press, New York, vol 2. p. 466; Parry, 1974. demostró que un océano enorme y previamente desconocido separaba al Nuevo Mundo de Asia, lo cual sirvió para consolidar la idea que América era un continente aparte $e^{7}$. Generalmente se cita como evidencia los planisferios de la Casa de la Contratación, los cuales abren una distancia sin precedente entre el Nuevo Mundo y las Molucas. Los planisferios construidos por Diogo Ribeiro en 1529, por ejemplo, expanden los $80^{\circ}$ de longitud que había puesto Waldseemüller entre América y Asia a la altura de la línea equinoccial, a $130^{\circ}$ entre Perú y las islas Molucas ${ }^{8}$ (Fig. 2). La cuenca marítima pequeña y perfectamente franqueable que Waldseemüller se había imaginado como parte del proceso de inventar a América se ha convertido en un abismo oceánico.

En el caso de los mapas de Ribeiro de 1529 , sabemos que el espacio que se abre entre el boceto incompleto del Nuevo Mundo y las costas fragmentarias de China y las Molucas consiste en mar, no tierra, gracias al desfile de barquitos que navegan desde el estrecho de Magallanes a las islas de la Especiería. Estos barcos no solamente marcan la ruta aproximada que tomó la flota de Magallanes por el Mar del Sur, sino que también indican de manera positiva que el espacio que les rodea es de hecho oceánico, y no solamente el espacio de lo desconocido. Como explica Philip Steinberg, durante el siglo XVI todavía no existía la convención de representar el espacio acuático como un espacio en blanco. Había que inferir la existencia del agua de la presencia cercana de costas continentales o insulares. Cuando se trataba del mar abierto, había que representarlo como tal mediante el uso de elementos supuestamente decorativos, como imágenes de barcos o animales marítimos ${ }^{9}$. Los barcos de Ribeiro, por lo tanto, no solamente conmemoran el viaje de Magallanes sino que anuncian el descubrimiento de lo que nosotros llamamos el océano Pacífico. Las dos imágenes de la Trinidad que aparecen hacia el noreste de las islas

The Discovery of the Sea. The Dial Press, New York, p. 258; Spate, 1979. The Spanish Lake. University of Minnesota Press, Minneapolis, p. 35.

8 Wroth, 1944. The Early Cartography of the Pacific. The Bibliographical Society of America, Papers, 38, pp. 87268, p. 151.

9 Steinberg, 2001. The Social Construction of the Ocean. Cambridge University Press, New York and London, pp. 104-105. 


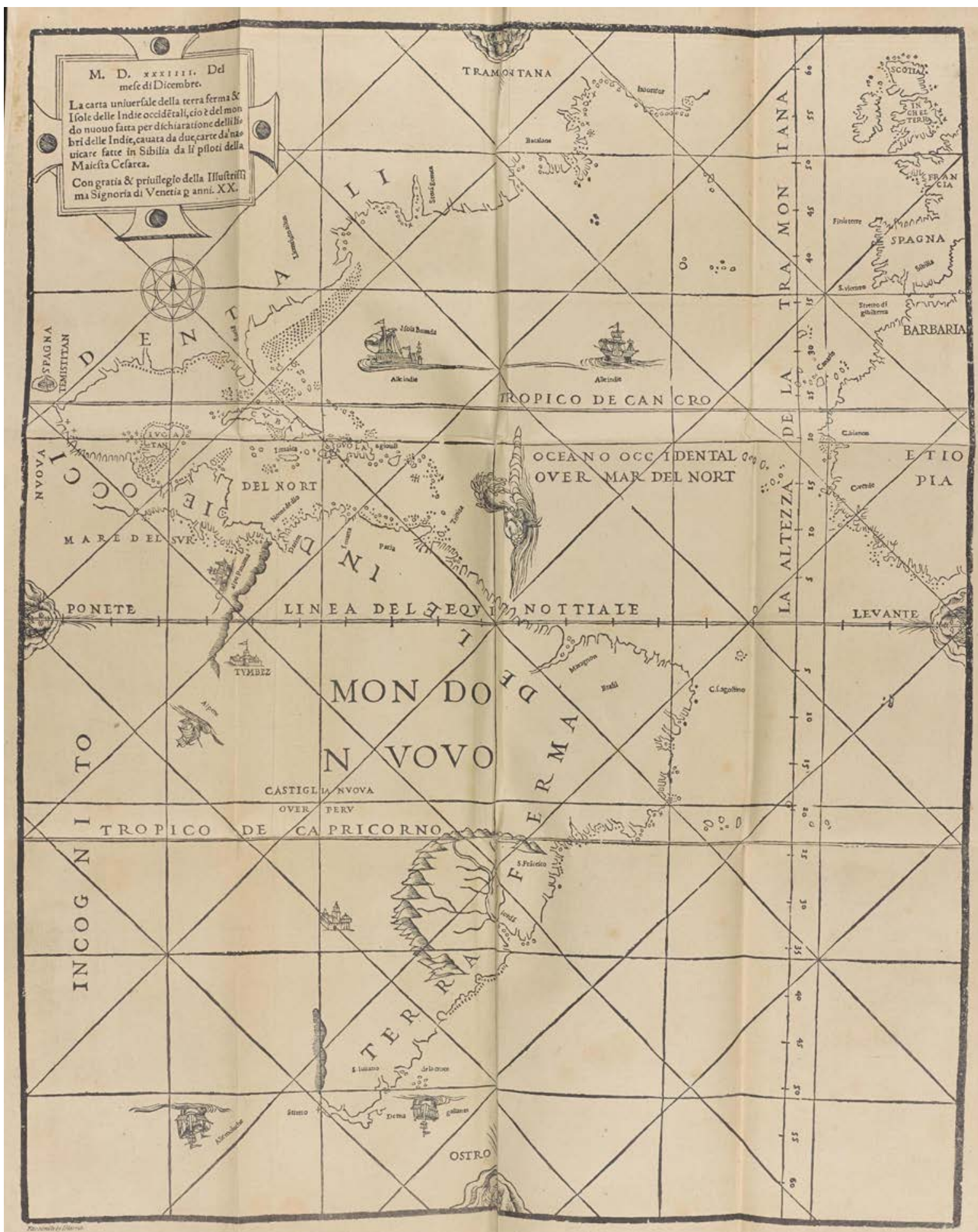

Fig. 2. El Nuevo Mundo y la Tierra Firme de las Indias Occidentales en el mapa que Giovanni Battista Ramusio prepara para su antología de textos sobre las Indias (Venecia, 1534). Albert and Shirley Small Special Collections Library, University of Virginia. 
Molucas juegan un papel crucial en este proyecto. La leyenda que les acompaña explica que la nave llegó a una latitud de $42^{\circ}$ Norte en su búsqueda por la ruta de regreso, antes de que se encontrase obligada a regresar a las Molucas por tempestades y vientos contrarios. A lo largo del camino, leemos, no encontró nada más que mar abierto. Según Oskar Spate, la implicación queda clara, the hapless last voyage of the Trinidad showed that the great new ocean extended indefinitely, with a vast breadth, into northern latitudes, $y$ que ya no sería posible soñar con la cercanía de Zipangu, o hacerse cuenta que el mar que se abría al otro lado del estrecho de Magallanes no era nada más que el Sinus Magnus de Ptolomeo ${ }^{10}$. Quedaba descubierto el océano Pacífico y el carácter insular del Nuevo Mundo.

Sabemos que algunos lectores de la cartografía sevillana la interpretaron de una manera parecida. Podemos citar como ejemplo el caso del cosmógrafo veneciano Giovanni Battista Ramusio, quien parece haber tenido acceso a la cartografía de la Casa de la Contratación a través de la intervención de su corresponsal Gonzalo Fernández de Oviedo, utilizándola para fabricar un mapa que tiene la peculiaridad de ser el primer mapa impreso que representa la totalidad de la costa atlántica de lo que para nosotros es el continente americano, y el primero en identificar al estrecho de Magallanes por este nombre ${ }^{11}$ (Fig. 3). Encontramos de nuevo imágenes de barcos que conmemoran el viaje de Magallanes a las Molucas pasando por el Estrecho, pero esta vez, las islas mismas no aparecen como parte de la imagen cartográfica. Por alguna razón se ha recortado la imagen sevillana, no sabemos si por decisión de Ramusio o no, para dejar fuera todo aquel espacio que en el planisferio de Ribeiro se extiende hacia el oeste de la ciudad de México Tenochtitlán, y que sirve para insistir que las islas Molucas forman parte del hemisferio castellano. Aquel espacio se reduce a una sola palabra, Incógnito, que aparece al lado izquierdo y marca el horizonte del conocimiento

10 Spate, 1979, op. cit., p. 57.

11 Buisseret y Holzheimer, 1992. The "Ramusio" Map of 1534: A Facsimile Edition. Newberry Library, Chicago.

12 Para el lugar de esta publicación en la literatura de viaje veneciano dedicado al Nuevo Mundo, véase Horodowich, cierto. No aparece por ninguna parte el nombre América, y el topónimo Nuevo Mundo parece aplicar solamente a lo que nosotros llamamos Sudamérica. Se reproduce el agnosticismo de la fuente con respecto al estatus de lo que aquí se llama la Terra Ferma de le Indie Occidentali, como isla o extensión del continente asiático, pero también se le aísla efectivamente de Asia, figurándolo como un lugar aparte. El espacio incógnito se convierte en una frontera ontológica entre este mundo no-todavía-americano figurado por el mapa, y aquel otro mundo asiático que no tiene nada que ver con este lugar. Los barcos que navegan por el Estrecho están de paso nomás por las Indias Occidentales, en camino a un destino lejano que no forma parte de ellas, excepto en el sentido político y solamente dentro de la imaginación española.

De esta manera, el mapa de Ramusio cumple su función como soporte cartográfico para el libro en el cual apareció, una antología de textos sobre las Indias compuesta de una traducción al italiano del Sumario de Oviedo, las tres décadas primeras de Pedro Mártir y dos cartas anónimas sobre la conquista del Perú, que fue publicado en Venecia con el título Libro primo della historia del' Indie Occidentali $(1534)^{12}$. El texto de Oviedo se elabora en la encrucijada entre el concepto heredado de las Indias y el concepto emergente de América, apegándose a la noción de que las Indias representan una zona geográfica ubicada en la Zona Tórrida, que abarcaba tanto a las Indias descritas por la tradición geográfica heredada como a las Indias nuevamente descubiertas en el Mar Océano, a la vez que insiste en la diferencia entre las dos Indias y la novedad de las Indias Occidentales para el conocimiento europeo ${ }^{13}$. Algo parecido se podría decir del texto de Pedro Mártir, que famosamente bautiza a los nuevos descubrimientos como un orbis novus, pero mantiene un interés activo en el resto de las Indias y en particular en la especiería. A Ramusio parece que le interesa intensificar este énfasis en

2018. The Venetian Discovery of America: Geographic Imagination in the Age of Encounters. Cambridge University Press, Cambridge and New York, pp. 64-66.

13 Wey Gómez, 2013, op. cit. 


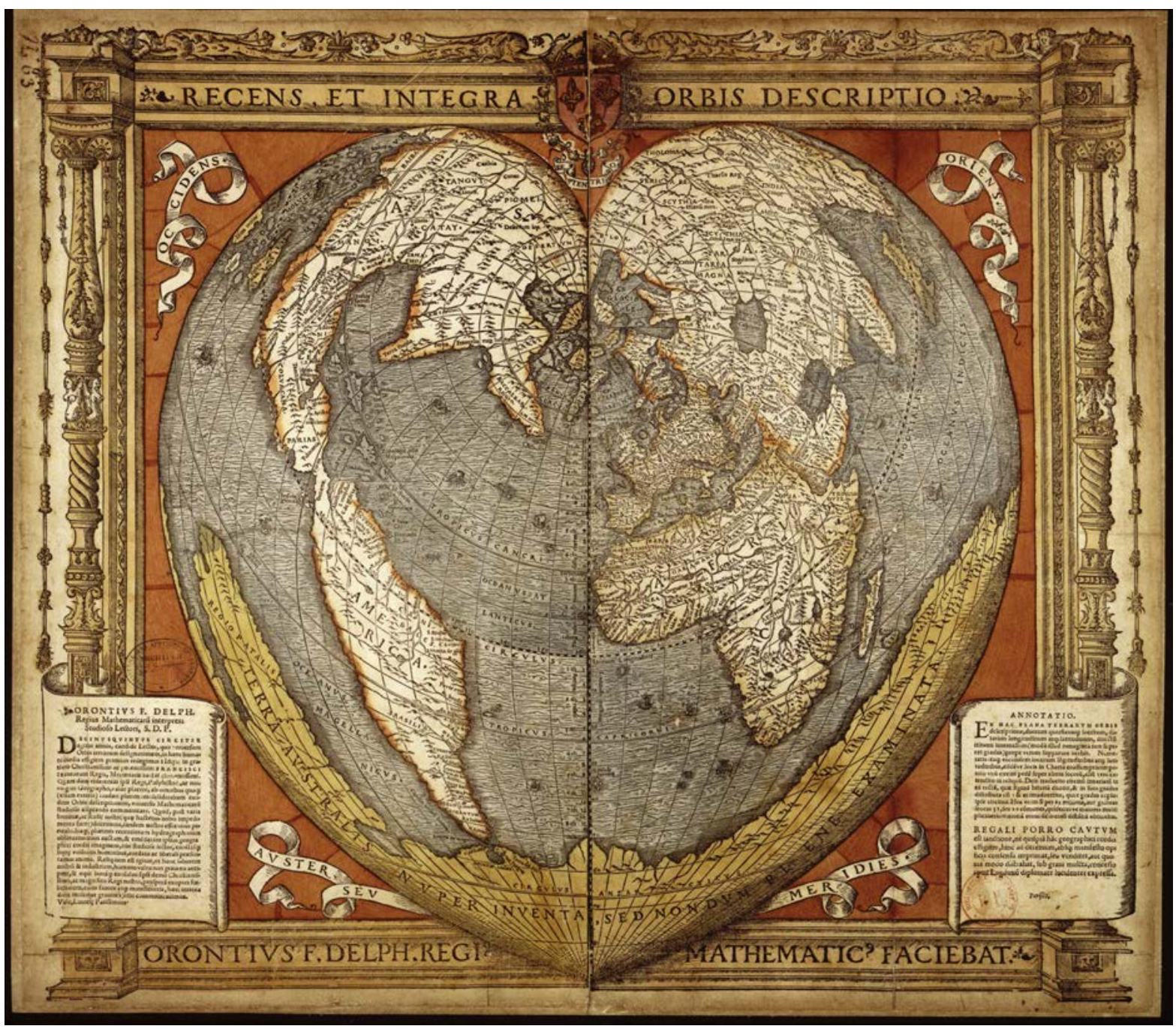

Fig. 3. El Nuevo Mundo y Asia aparecen como un solo continente continuo en Oronce Finé. Recens et integra orbis descriptio (Paris, 1534-1536). Biblioteca Nacional de Francia.

la diferencia y la novedad. Según Horodowich, modifica el texto de Mártir para enaltecer el descubrimiento colombino de una manera más marcada que el original, y de esta forma indica al lector que las tierras descubiertas por el almirante son, de hecho, un Nuevo Mundo, diferente de Asia ${ }^{14}$. También prepara este mapa, que sirve para poner en olvido a las Indias más allá del Mar del Sur, para condenarlas a la irrelevancia, y para sugerir al lector que debería pensar en las Indias Occidentales como un lugar aparte.

\section{UN PASAJE AL MAR DEL SUR}

Los planisferios sevillanos, sin embargo, se prestan a otras interpretaciones, particularmente cuando tomamos en cuenta el propósito diplomático que estaban destinados a servir, y los leemos a la luz de los relatos de la primera circunnavegación del mundo que salieron a la imprenta durante la misma década. Los planisferios, de hecho, no estaban diseñados para dar fe a la enorme anchura de lo que nosotros llamamos el océano Pacífico, 
sino para contrarrestar las implicaciones políticas de lo que había descubierto Magallanes. Aunque por comparación con mapas anteriores alargan la distancia entre América y Asia, no utilizan los mayores valores disponibles, como los que se encontraban en el cuaderno de bitácora del piloto Francisco de Albo, y de esa manera evitan que las islas de la Especiería pasen al otro lado del antimeridiano, a territorio portugués ${ }^{15}$. A la luz de este propósito, los barcos que sirven para marcar la existencia de un espacio oceánico en el planisferio de Ribeiro también se pueden entender como símbolos de la conquista de ese mismo mar por la flota española. Por eso se encuentran rodeados por dibujos de instrumentos náuticos que, según Surekha Davies, celebran el arte de la navegación astronómica, o sea, la serie de técnicas favorecidas por los cosmógrafos de la Casa de la Contratación como las mejores para la navegación en alta $\operatorname{mar}^{16}$. Lejos de admitir que el Nuevo Mundo queda aislado de Asia por la distancia entre los dos, el planisferio de Ribeiro intenta atarlos juntos con aquella cadena de naves que atraviesa el espacio entre ellos. De esta manera, insiste en que España tenía la capacidad necesaria para ejercer dominio sobre todas las Indias descubiertas y por descubrir a su lado de la frontera con Portugal en el extremo occidental del Mar del Sur. El aislamiento del Nuevo Mundo que se observa en el mapa de Ramusio, por lo tanto, se tiene que entender no como la transferencia inocente del conocimiento geográfico de Sevilla a Venecia, del manuscrito a la estampa, sino como una traducción violenta de la cartografía sevillana que apropia su imagen del Nuevo Mundo para servir un programa intelectual y retórico muy diferente del original.

Cuando resistimos la tentación de recortar los planisferios sevillanos como tantas veces se les

15 Albo, 1837. Diario o derrotero del viage de Magallanes dese el cabo de San Agustín en el Brasil, hasta el regreso a España de la nao Victoria. En Fernández de Navarrete (Ed.), 1765-1844. Colección de los viages $y$ descubrimientos que hicieron por mar los españoles desde fines del siglo XV: con varios documentos inéditos concernientes a la historia de la Marina Castellana y de los establecimientos españoles en Indias. Vol. 4, Imprenta Real, Madrid, pp. 209-247.

16 Davies, 2003. The Navigational Iconography of Diogo Ribeiro's 1529 Vatican Planisphere. Imago Mundi: The International Journal for the History of Cartography, recorta, el espacio en blanco ya no es ni el incógnito absoluto de Ramusio ni el enorme océano que identifican en aquellos mapas los historiadores mencionados. Para entender bien ese espacio hemos de tener en cuenta la ambigüedad inherente del uso de barcos, animales marítimos e islas oceánicas para marcar la existencia de mar abierto. No tiene sentido suponer que el poder significativo de alguna de estas imágenes podía extenderse de manera indefinida, hasta chocar con alguna costa o con el borde del mapa mismo, particularmente en el caso de este espacio en particular, que a las alturas de 1529 solamente se había cruzado tres veces, en una sola dirección, a la altura de la Zona Tórrida. Hay que suponer, por lo contrario, que en algún lugar imposible de definir con precisión se acababa el poder significativo de la imagen que dice lo que me rodea es mar abierto, y se pasa, sin que uno se dé cuenta, al espacio en blanco de lo desconocido ${ }^{17}$. Cualquier lector consciente de esta ambigüedad se daría cuenta de que, aunque el planisferio de Ribeiro traza una banda de océano desde el estrecho de Magallanes hasta las Molucas, realmente no afirma nada sobre la naturaleza del espacio hacia el Norte o hacia el Sur de aquel trayecto, con la excepción de aquellas zonas donde interviene algún signo adicional, como el área identificada como océano por las imágenes de la Trinidad. Nosotros, acostumbrados a la imagen moderna del mundo donde dominan los espacios vacíos del océano, dejamos que aquel espacio en blanco represente mares por descubrir, pero el lector de la época muy probablemente habría imaginado este espacio de otra manera, gracias al prejuicio impuesto por la cosmografía renacentista que la tierra tenía que dominar sobre el agua en la superficie terrestre ${ }^{18}$. Aquel lector hubiera rellenado los espacios que nosotros interpretamos como mar

55(1), pp. 103-112.

17 Para la representación de lo desconocido en la cartografía, véase Lois, 2018. Terrae incognitae: Modos de pensar y mapear geografías desconocidas. Editorial Universitaria de Buenos Aires, Buenos Aires.

18 Randles, 2000. Classical Models of World Geography and Their Transformation Following the Discovery of America. En Geography, Cartography and Nautical Science in the Renaissance: The Impact of the Great Discoveries. Ashgate/Variorum, Aldershot, Hampshire, Great Britain; Burlington, Vt., USA, pp. 5-76. 
abierto con islas e incluso continentes hipotéticos, quizás un puente geográfico entre la China y lo que nosotros llamamos Norteamérica más allá de los $42^{\circ}$ de latitud norte alcanzados por la Trinidad, o alguna versión de la Terra Australis en el espacio que se abría hacia el sur de la ruta magallánica. Estas alternativas cabían mucho mejor en su horizonte de expectativas que un océano enorme y vacío.

Este tipo de lectura de los planisferios sevillanos encontraba apoyo en los relatos de la primera circunnavegación del mundo que se publicaron durante los años entre la llegada de la Victoria a Sevilla (1522) y la finalización del Tratado de Zaragoza (1529), mediante el cual Carlos V cedió las islas Molucas a Portugal. Me refiero a la carta de Maximilian von Sevenborgen (alias Maximilianus Transylvanus) publicada por primera vez en Colonia con el título De Moluccis insulis (1523, 1969), el relato de la circunnavegación por Antonio Pigafetta publicado por primera vez en París con el título Le voyage et nauigation, faict par les Espaignolz es Isles de Mollucques $(1525,1969)$ y el relato "De orbe ámbito" que aparece en la quinta década de Pedro Mártir de Anglería ${ }^{19}$. Von Sevenborgen era pariente de Cristóbal Haro, quien había financiado la expedición, y servía como secretario de Carlos $\mathrm{V}$, mientras Mártir servía como cronista oficial del Consejo de Indias. No sorprende, por lo tanto, que ambos textos sirvan los mismos propósitos propagandísticos que los planisferios sevillanos. Cuando citan distancias o longitudes, siempre cuadran con la ambición española de reclamar control sobre las islas Molucas. Cuando relatan la travesía del Pacífico por la flota de Magallanes, hacen todo lo posible para minimizar el sufrimiento de los hombres, y así evitar la implicación de que

19 Anghiera, 1530. De orbe nouo Petri Martyris ab Angleria Mediolanensis Protonotarij Cesaris senatoris decades. Apud Michael*e d'Eguia, Compluti; Anglería, 1989. Décadas del Nuevo Mundo. Ediciones Polifemo, Madrid. En 1530 se publica por primera vez el texto completo de las Décadas de Mártir, pero según Ramón Alba, el capítulo dedicado a la expedición de Magallanes fue escrito mucho antes, quizás en el mismo año que regresó la Victoria. Anglería, 1989, op. cit., p. 36. Los textos de Transylvanus, Mártir y Pigafetta han sido ampliamente reproducidos, pero para examinar la edición parisina del tercero véase Pigafetta, 1969. The Voyage of Magellan: The Journal of Antonio Pigafetta. A Translation by Paula Spurlin Paige la distancia desde el Nuevo Mundo a la Especiería era demasiado grande para la proyección eficaz del poder español. Aun el relato de Pigafetta, desarrollado y publicado fuera del ámbito de la corte habsburga, trabaja a favor de los intereses españoles. Aunque dramatiza la miseria sufrida durante la travesía con una intensidad grotesca, provee datos sobre ciertas longitudes que sugieren que el Mar del Sur es relativamente estrecho. Cuando el cosmógrafo francés Oronce Finé utilizó la edición parisina de Pigafetta, la única disponible, para determinar las dimensiones del Mar del Sur en su mapa cordiforme del mundo de 1534-1536, puso solamente $80^{\circ}$ de longitud entre Sudamérica y Asia, una distancia más parecida a la que aparece en Waldseemüller que a la que señala Ribeiro (Fig. 4). Dada la circulación limitada que debían haber tenido los planisferios, los que se interesaban por los descubrimientos de Magallanes tuvieron que acudir a estos textos mentirosos o defectuosos. Entonces, en vez de hablar de un descubrimiento del Pacífico por Magallanes, habría que hablar de un encubrimiento del Pacífico por la corona española ${ }^{20}$.

Ahora, este encubrimiento no era suficiente de por sí para sugerir que América formaba parte del continente asiático. Después de todo, Waldseemüller había inventado el concepto de América como una cuarta parte insular sin tener que imaginar que un océano de dimensiones inéditas intervenía entre Asia y su nuevo continente. En su mapa de 1507, la distancia entre América y Asia es breve y queda poblada de una serie de islas que funcionan como puente entre las dos masas de tierra (Fig. 5). Quizás por eso le fue posible cambiar de opinión en su Carta marina de 1516, en la cual

from the Edition in the William L. Clements Library, University of Michigan, Ann Arbor (P. S. Paige, Trans.). Prentice-Hall, Englewood Cliffs, NJ.

20 Este párrafo resume el argumento del tercer capítulo de Padrón, 2020. The Indies of the Setting Sun: How Early Modern Spain Mapped the Far East as the Transpacific West. University of Chicago Press, Chicago. Para un análisis de la carta de von Sevenborgen que va mucho más allá de su papel como propaganda imperial, véase Onetto, 2017. Modernidad, historicidad y construcción de territorialidades desde un pasaje-mundo. El estrecho de Magallanes tras su "Descubrimiento". Magallania, 45(2), pp. 37-58. 
nuestra Sudamérica aparece como una extensión del continente asiático. Un océano enorme tampoco le hacía falta a uno de los seguidores más relevantes de Waldseemüller, el cosmógrafo suizo Sebastian Münster, para identificar el Nuevo Mundo como isla en su mapa de 1538, el primer mapa impreso que representa al Nuevo Mundo de esta manera. Cuando confrontamos esta imagen con su mapa de Asia y las Indias Orientales para producir lo que Thomas Suárez llama el primer mapa impreso del océano Pacífico, es precisamente el océano Pacífico lo que no aparece por ninguna parte ${ }^{21}$. O sea, aparece el topónimo Mare pacificum cerca de la desembocadura del Fretum Magellani, pero la cuenca marítima entre el Nuevo Mundo y Asia no tiene las dimensiones del océano que nosotros conocemos, y no sirve para alejar al Nuevo Mundo del Viejo (Fig. 6). Todo lo contrario, sus dimensiones no parecen ser mayores que las del mar sin nombre que se interpone entre Asia y América en el mapa de Waldseemüller, aunque el mapa de Münster carece de una escala que nos permita confirmar esta impresión puramente visual. Además, cuenta con un archipiélago que se extiende desde el continente asiático hasta América y aún logra incluirla, no como una cuarta parte del mundo, sino como una enorme isla indiana ${ }^{22}$.

Para que se popularizara la idea de que América formaba parte de Asia, como de hecho se popularizó, era necesario tomar en cuenta otras noticias que por pura coincidencia discurrían por Europa más o menos a la misma vez que se difundía el relato de von Sevenborgen. Se trata de las cartas de Hernán Cortés sobre el imperio de los Mexica y su conquista, publicadas por primera vez en Sevilla y pronto traducidas a otros idiomas, incluyendo el latín (1522, 1524). A muchos lectores lo que Cortés dejó escrito sobre la cultura urbanizada del valle central de México les recordaba lo que habían leído sobre las ciudades de Catayo y Mangi, llegando a la conclusión de que la Nueva España tenía que

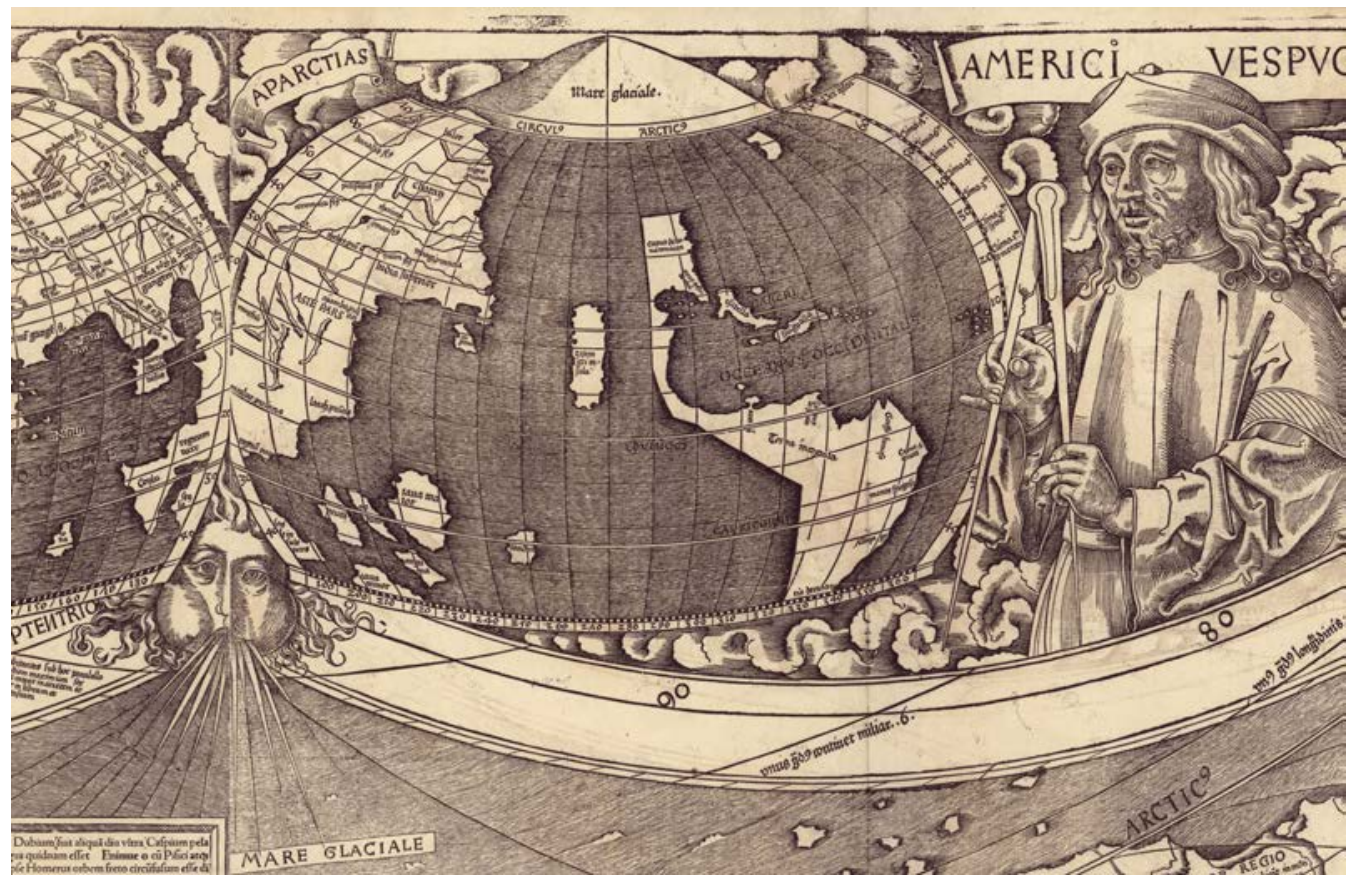

Fig. 4. Un espacio breve separa a América de Asia en este detalle de Martin Waldseemüller. Universalis cosmographia secundum Ptholomaei traditionem et Americi Vespucii alioru[m] que lustrationes (Strasbourg, 1507). Biblioteca del Congreso, Washington, DC.

21 Suárez, 2004. Early Mapping of the Pacific: The Epic Story of Seafarers, Adventurers, and Cartographers who Mapped the Earth's Greatest Ocean. Periplus, Singapore.
22 Davies, 2011. America and Amerindians in Sebastian Münster's "Cosmographiae universalis libri VI" (1550). Renaissance Studies, 25, 351-373. 


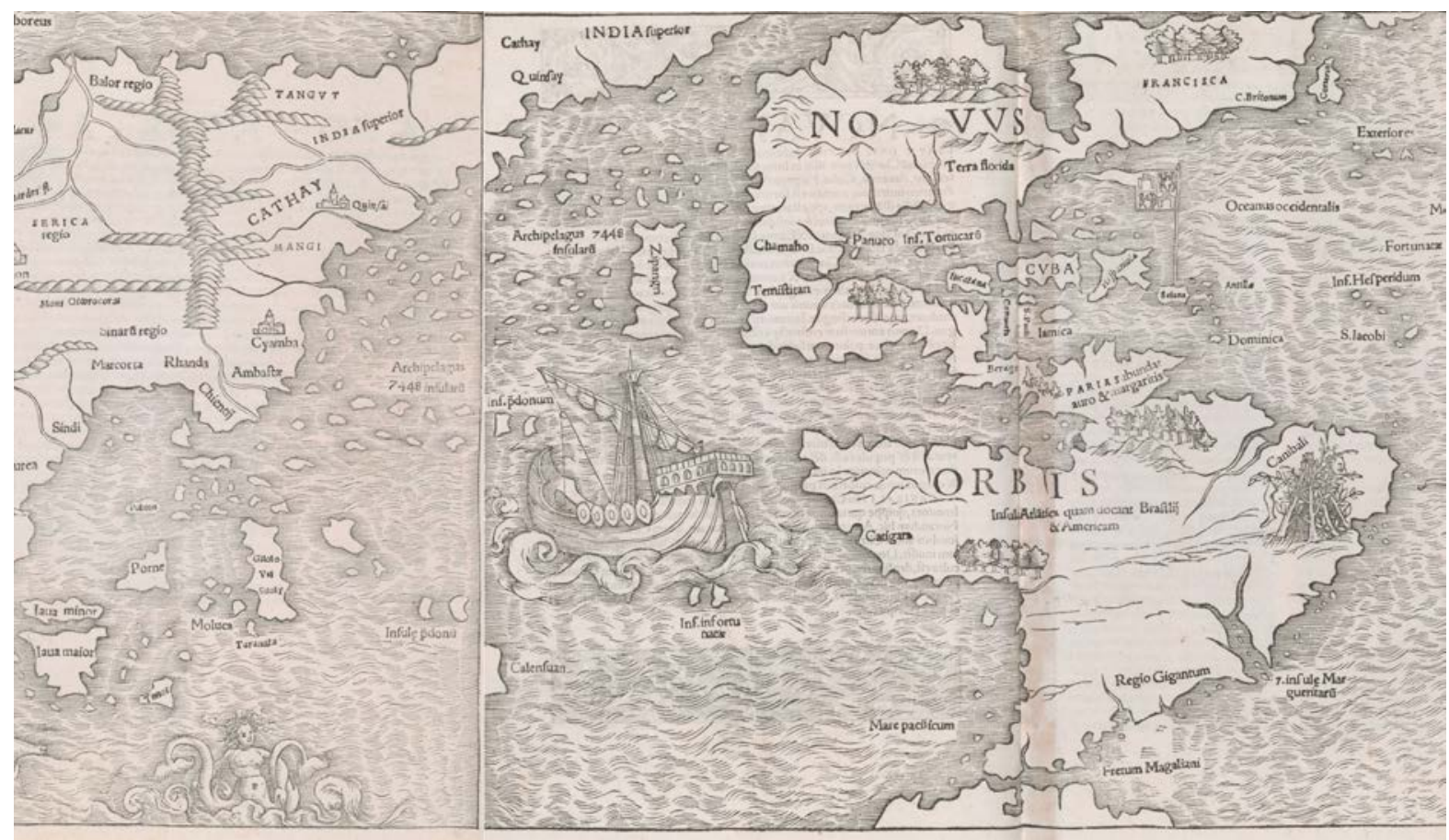

Fig. 5. El Pacífico de Münster se hace visible cuando empatamos su mapa del Nuevo Mundo con este detalle de su mapa de Asia. Ambos mapas sacados de Claudius Ptolemy. Geographia uniuersalis, uetus et noua (Basil, 1545). Renaissance Exporation Map Collection, Stanford University.

formar parte del continente asiático ${ }^{23}$. Esta lógica pudo influir a Oronce Finé en su decisión de mantener una distancia breve entre el Nuevo Mundo y Asia, e incluso de cartografiar lo que nosotros llamamos Norteamérica con Asia. También tuvo influencia sobre el pensamiento del cosmógrafo alemán Caspar Vopel, cuyo mapa del mundo sigue por las mismas líneas, representando a Norteamérica como parte de Asia. Hasta incluye una leyenda en latín que explica cómo muchos identificaban a Moctezuma con el Gran Khan y a Tenochtitlán con Quinsay ${ }^{24}$. El mismo Vopel no llega a semejante extremo, pero a base de sus conversaciones con veteranos de la conquista de México, explica la leyenda, llega a pensar que Catayo y Mangi deben quedar muy cerca de la Nueva España. De hecho, en

23 Stevenson, 1921. Terrestrial and Celestial Globes: Their History and Construction. Yale University Press for the Hispanic Society of America, New Haven, 106-107.

24 Vopel construyó su mapa en 1546 , pero ahora solamente lo conocemos a través de dos copias posteriores. Aquí se reproducen detalles de la copia hecha en Venecia en 1558 por Alessandro Vavassore que ahora forma parte de el mapa mismo, ni siquiera cinco grados de longitud separan a Hispania Nova de Mangi y Chatay [sic]. Mientras tanto, el golfo de México lleva el nombre Mare Cathayum, la isla de Hispaniola se identifica con Zipangu, y una sola costa continua corre desde la desembocadura del estrecho de Magallanes hasta Asia Magna y su multitud de islas. Otros fabricantes de mapas y globos llegaron a la misma conclusión. De hecho, en la mayoría de las representaciones cartográficas de la geografía global producidas en Europa durante el segundo cuarto del siglo XVI, el Nuevo Mundo figura como una extensión del continente asiático ${ }^{25}$.

En este mapa enorme, originalmente fabricado en 1546 y dedicado al emperador Carlos V, el estrecho de Magallanes sigue siendo

la colección de la Biblioteca Houghton de la Universidad de Harvard. El mapa entero se encuentra en línea en alta resolución en el sitio web de la Biblioteca de Harvard. https://iiif.lib.harvard.edu/manifests/view/ids: 7723780 . Acceso el 11 de julio del 2019.

25 Stevenson, 1921, op. cit., pp. 1 y 168-169. 

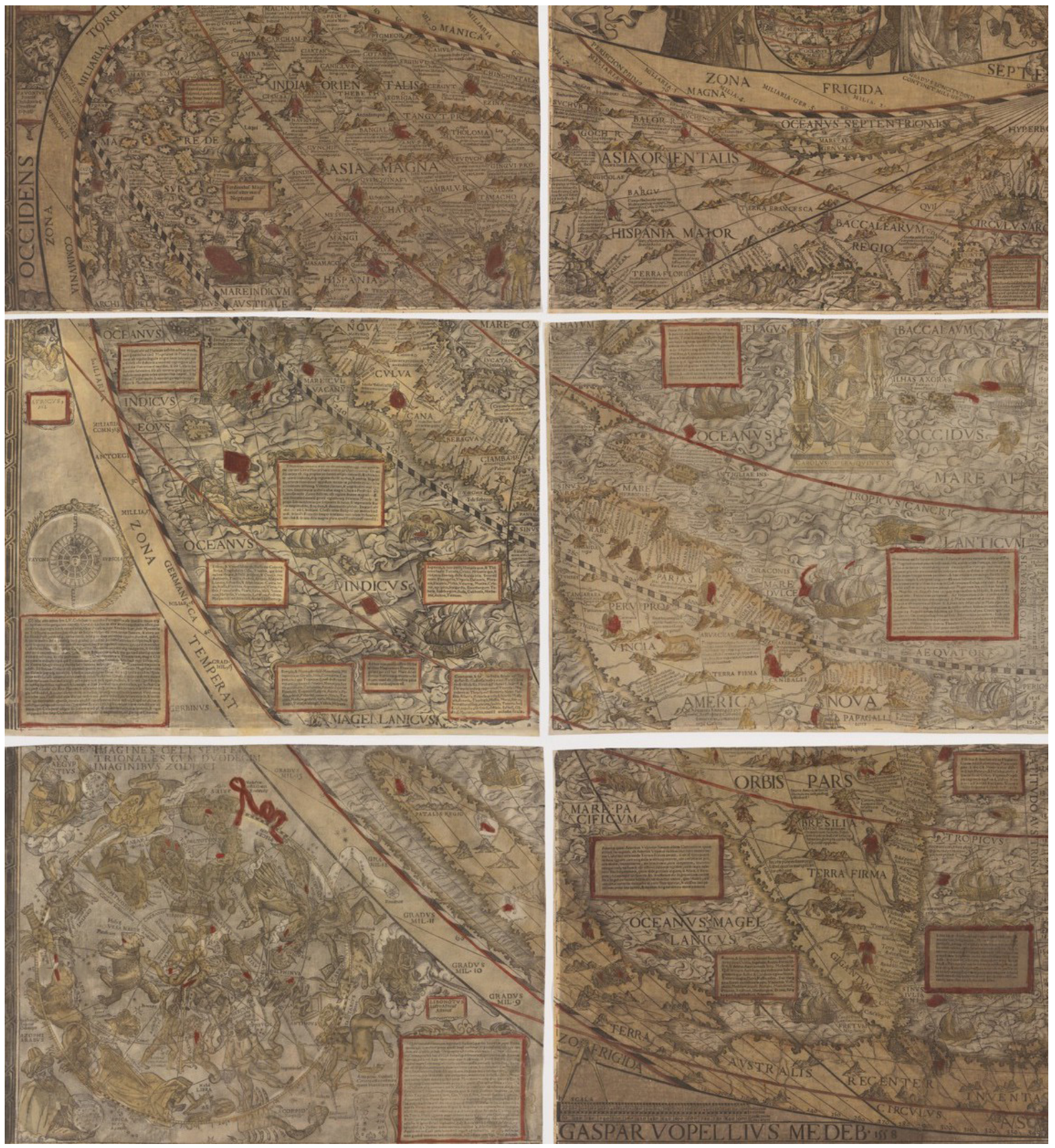

Fig. 6. El Mar del Sur en este detalle del mapamundi de Caspar Vopel, copiado por Alessandro Vavassore.

Caspar Vopel. Nova et integra universalisque orbis totius ... descriptio (Venice, 1559).

Harvard University Library.

lo que había sido cuando solamente se imaginaba la posibilidad de su existencia, un paso marítimo a las riquezas de las Indias. De nuevo encontramos un barco de vela que parece haber desembocado del Fretum Magellanicum y ahora navega por las aguas del Oceanus Magellanicus rumbo a las Indias. Gracias a la proyección cordiforme, esta cuenca marítima toma la forma de un corredor entre el Estrecho y las islas del sudeste asiático. La costa de la Terra Australis forma su pared 
izquierda, mientras la costa de America Nova Orbis Pars forma la pared derecha. Esta costa se funde con la de Asia para formar una sola línea casi recta que guía el ojo desde el Estrecho hasta el archipiélago del sudeste asiático. Los nombres del mar que bañan esta costa van cambiando, primero a Mare Pacificum y luego a Oceanus Indicus Magellanicus, Mare Indicum Australe, Oceanus Indicus Eous, y por fin, Mare de Sur. Aparece a lo largo del camino una serie de animales marítimos que podrían presentar una amenaza a la navegación, pero también se encuentra una serie de barcos a toda vela que no parecen tomarles en cuenta. Cerca del archipiélago se observa una batalla marítima que quizás sirva para conmemorar la guerra entre España y Portugal por el control de las Molucas, particularmente si interpretamos al rey montado en una ballena justo al Sur de este encuentro como una figura del poderío portugués, que había llegado a la región desde el Oeste (Fig. 7). No se dice nada de la derrota militar sufrida por los castellanos, ni del Tratado de Zaragoza (1529) mediante el cual Carlos V cedió las Molucas a Portugal. Al contrario, aparece un Magallanes en armadura montado en una ballena, listo para ensartar el archipiélago con su bandera/lanza. Encima de su figura encontramos la leyenda Fernandus Magellanus alter maris Neptunus. A través de todos estos efectos visuales, estas inclusiones y estos silencios, el mapa de Vopel lleva a cabo de manera admirable el programa propagandístico que había empezado con el texto de von Sevenborgen y los planisferios de la Casa de la Contratación. El océano Pacífico, si alguna vez se reconoció su existencia, queda totalmente encubierto, borrado. América se mapea como parte de unas Indias más amplias, que incluyen los países e islas del Este y Sudeste asiático, y hasta la Terra Australis. El estrecho de Magallanes se convierte en el punto de entrada a este imperio en el Mar del Sur.

\section{UN PASAJE AL DESASTRE}

Es sumamente irónico que este mapa

26 Flint y Flint, 2013. No Settlement, No Conquest: A History of the Coronado Entrada. University of New Mexico Press, Albuquerque; Kelsey, 1998. Juan Rodríguez fuese fabricado solamente algunos años después de que una serie de expediciones lanzadas desde Nueva España hacia el Norte y el Oeste hubiera puesto esta imagen de la geografía de los nuevos descubrimientos en tela de juicio. Estas expediciones representaban la culminación de un ciclo de actividad que había empezado poco después de la conquista de Tenochtitlán, cuando Hernán Cortés y sus contemporáneos se interesaron en las oportunidades que presentaba la exploración de la costa pacífica de lo que es ahora México y California, y del interior de lo que es ahora el Sudeste de Estados Unidos. Entre 1526 y 1542 se buscó un nuevo paso marítimo al Mar del Sur, se trató de seguir la costa de América hasta China y la Especiería, se lanzó una nueva expedición transpacífica para colonizar las islas del Sudeste asiático, y se marchó a la conquista de los países fabulosos de Cíbola y Quivirá. Todos estos proyectos fracasaron, y según Harry Kelsey, Miguel León-Portilla, y Richard y Shirley Flint, su fracaso contribuyó de manera significativa a consolidar la idea de que América era un mundo aparte, separado de Asia por el Mar del Sur ${ }^{26}$. Arguyen que cuando Coronado descubrió manadas de bisontes donde debería haber encontrado a Quivirá, se hizo evidente que América no se parecía al mundo descrito por Marco Polo; que cuando Cabrillo descubrió que la costa de California no giraba hacia el oeste para unirse con la costa chinesca, se abandonó la idea de que América y Asia podrían formar parte de un solo continente; y que cuando la colonia establecida por Villalobos en el Sudeste asiático se desintegró gracias a la falta de una ruta de regreso a Nueva España para pedir ayuda, el proyecto del imperialismo transmagallánico cayó en desgracia. Según los historiadores citados, estos descubrimientos lograron lo que el supuesto descubrimiento del Pacífico por Magallanes nunca logró, imponer la idea de que el Nuevo Mundo mejor se entendía como una isla de estatus continental separada de Asia por el Mar del Sur.

De hecho, algunas fuentes conjugan el fracaso de estas expediciones con la tesis de

Cabrillo. Huntington Library, San Marino, CA; LeónPortilla, 2005. Hernán Cortés y la Mar del Sur. Algaba, Madrid. 


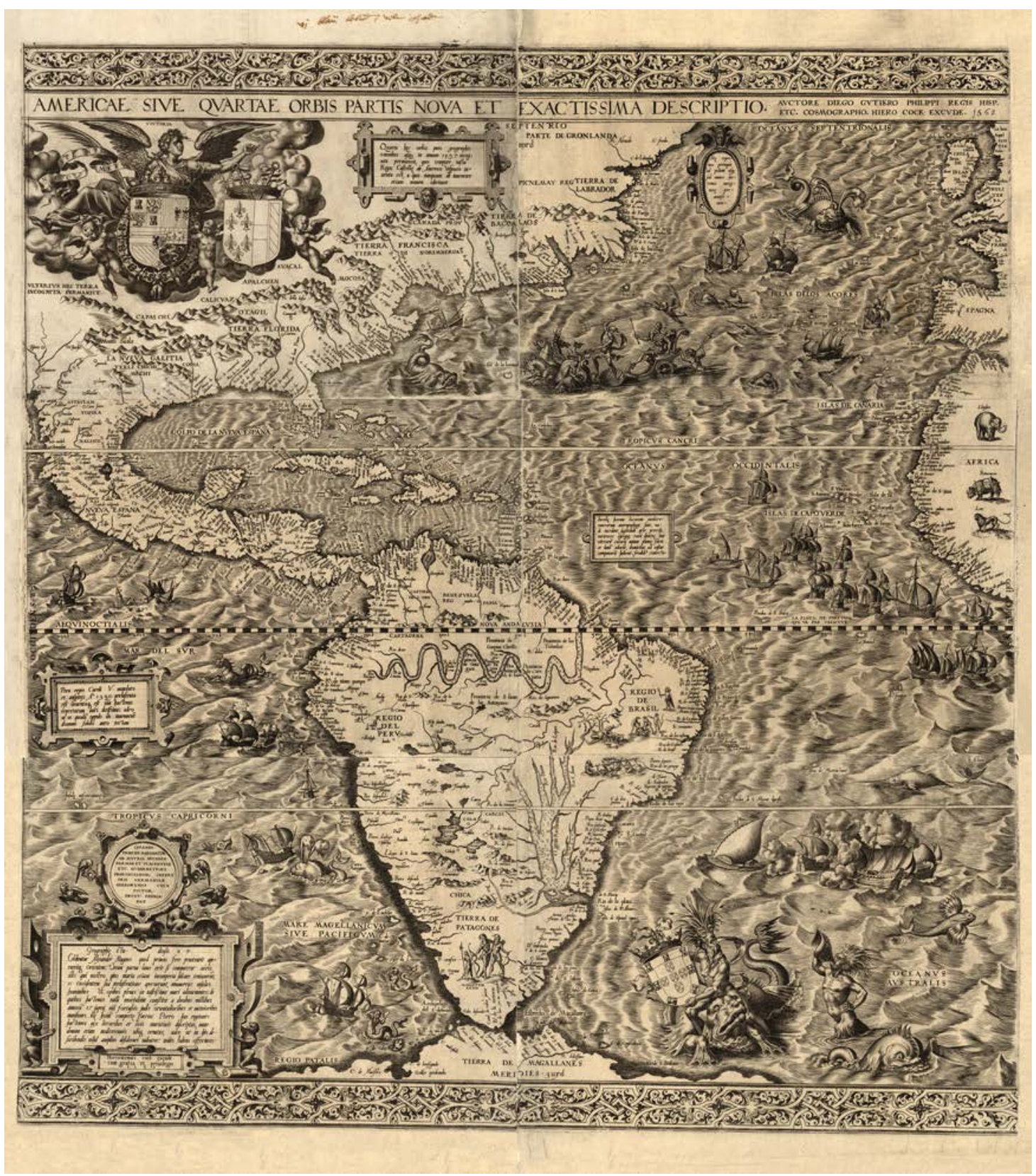

Fig. 7. El Mar del Sur es el espacio del desastre marítimo en Diego Gutiérrez.

Americae sive quartae orbis partis nova et exactissima descriptio (Amberes, 1562).

Biblioteca del Congreso, Washington, D.C.

la insularidad americana. Entre ellas destaca la Historia general de las Indias de Francisco López de Gómara, un texto diseñado para justificar y aún celebrar la conquista de América

27 Este párrafo y el siguiente condensan la lectura de Gómara que hago en Padrón, 2016. (Un)Inventing America: The por España, y más específicamente la conquista de México por Hernán Cortés (1552)27. Los capítulos dedicados a lo que Gómara llama la "Empresa de la Especiería" relatan el fracaso

Transpacific Indies in Oviedo and Gómara. Colonial Latin American Review, 25(1), pp. 16-34. 
de todas las expediciones transpacíficas desde Magallanes a Villalobos y comunican la amargura de la élite castellana frente a la decisión del emperador de abandonar el trato de la especiería a Portugal ${ }^{28}$. Los capítulos dedicados a la exploración cortesiana del Mar del Sur, así como los que tratan de la expedición de Coronado en pos de las riquezas de Cíbola, desdeñan los sueños vacíos que guiaron a estos proyectos, $y$ se burlan del desperdicio de recursos que ocasionaron $^{29}$. Esto era posible para un autor tan evidentemente imperialista como Gómara en gran parte gracias al descubrimiento y conquista de México y Perú, que sirvieron para transformar al Nuevo Mundo de un obstáculo en el camino hacia el verdadero premio, la Especiería, en la misma joya de la corona imperial. Conquistados Anahuác y Tawantinsuyo, no importaba tanto que Maluku quedara fuera de alcance, y se podía tratar del fracaso del proyecto transmagallánico con mayor franqueza. La obra de Gómara no solamente reflejaba este cambio, sino que contribuyó a su realización ${ }^{30}$.

Para Gómara, aquel Nuevo Mundo que brillaba con luz propia era sin duda una isla de estatus insular, la cuarta parte del mundo y el hogar de una estirpe de la familia humana de costumbres particularmente salvajes ${ }^{31}$. En esto, el cronista soriano se encontraba en la vanguardia del pensamiento europeo. Durante los veinte años posteriores a la primera publicación de la Historia general de las Indias se fue popularizando la teoría de Waldseemüller, gracias en cierta medida a los eventos comentados (Cortés, Pizarro, Coronado, etc.) y, en otra, al surgimiento de los Países Bajos como el centro más importante de producción cartográfica europea. América, por cierto, no fue descubierta, pero tampoco fue solamente inventada. Fue también impuesta por las fuerzas del mercado en mapas y otros materiales geográficos

28 López de Gómara, 1979. Historia general de las Indias y Vida de Hernán Cortés. Edición de J. Gurría Lacroix. Biblioteca Ayacucho, Caracas, pp. 136-152.

29 Ibidem, pp. 303-306. López de Gómara, 2007. Historia de la conquista de México. Edición de J. Gurría Lacroix. Recuperado de http:// archive.org/details/GomaraFranciscoLopezDe. HistoriaDeLaConquistaDeMexico2007, p. 379.

30 Es de notar que la publicación del texto de Gómara fue cuyo centro se desplazó hacia el Norte durante la segunda mitad del siglo XVI hasta llegar a descansar en aquellas partes del continente donde la idea de América siempre había recibido mayor acogida. En España se prefería el nombre las Indias para hablar de los nuevos descubrimientos, aun cuando se trataba de un continente insular, como en el caso de Gómara. Tan exótico era el nombre América durante la primera mitad del siglo que Bartolomé de las Casas, en 1527, encontró necesario explicar al lector hispanoparlante de su Historia de las Indias que aquel nombre que se veía en mapas fabricados en el extranjero se debía al error de atribuir el descubrimiento del Nuevo Mundo a Vespucio y no a Colón ${ }^{32}$. Durante medio siglo, América, según el Corpus del Nuevo Diccionario Histórico del Español,(CNDHE), se encuentra como nombre para designar el Nuevo Mundo solamente en una traducción española de la Cosmografía de Pedro Apiano, un texto escrito originalmente en alemán y en la Historia de las Indias de Bartolomé de las Casas, en un pasaje en el cual el fraile lo identifica como un topónimo que circula en el extranjero ${ }^{33}$. No es hasta 1572 , según dicho repertorio, que aparece un texto que utiliza América como nombre para Sudamérica, sin calificaciones o explicaciones: la Historia de los Incas de Pedro Sarmiento de Gamboa. Ya para entonces había aparecido aquel monumento de la cartografía flamenca, el Theatrum orbis terrarum de Abraham Ortelio, estructurado a base de la división del mundo en cuatro (potencialmente cinco) partes, entre ellas América.

Ejemplos de la cartografía oficial de la Casa de la Contratación ahora empezaban a pasar a la imprenta en las páginas de las diferentes ediciones del Theatrum y en otros productos cartográficos, entre ellos un mapa monumental de América fabricado en Amberes por Hieronymous Cocke a base de un modelo del cosmógrafo sevillano

prohibida por la Corona por un tiempo, pero no por lo que tenía que decir sobre estas expediciones o sobre la geografía indiana

31 López de Gómara, 1979, op. cit., pp. 7-8, 27 y 303.

32 Las Casas, 1986. Historia de las Indias (Vols. 1-3). Edición de A. Saint-Lu. Biblioteca Ayacucho, Caracas, p. 557.

33 Véase el CNDHE en http://web.frl.es/CNDHE/org/ publico/pages/consulta/entradaCompleja.view. Acceso el 16 de julio del 2019. 
Diego Gutiérrez, y dedicado a la duquesa de Parma, Margarita de Austria, hija natural de Carlos $\mathrm{V}$, y su regente en los Países Bajos desde 1559 a $1567^{34}$. Gutiérrez era miembro de una familia de fabricantes de mapas e instrumentos náuticos asociada con aquella institución, y contaba entre los cosmógrafos que mantenían el mapa oficial del mundo de la corona española, el padrón general, del cual los mapas de Ribeiro y Chaves eran copias. Podemos suponer, por lo tanto, que la imagen de América proveída por Gutiérrez formaba parte de un planisferio entero, parecido a estos precursores. Una de las transformaciones básicas que ocurrió en la traducción del conocimiento cartográfico manuscrito y sevillano al medio de la imprenta flamenca, entonces, fue la misma que vimos en el caso de Ramusio, el recorte. A la visión amplia y abarcadora de las Indias que hubiera aparecido en el planisferio de Gutiérrez se le ha aplicado un marco que recorta su geografía, dejando lo que nosotros conocemos como Sudamérica, Centroamérica, México y Baja California, junto con la costa atlántica de Norteamérica, pero dejando fuera toda aquella zona donde se definía el estatus del Nuevo Mundo como isla o como parte del continente asiático. El programa iconográfico es detallado, la calidad del trabajo alto y las dimensiones $(100 \times 102$ $\mathrm{cm})$, impresionantes.

Esta vez, sin embargo, el recorte del planisferio sevillano se lleva a cabo con mayor certeza. De nuevo se recorta el espacio transmagallánico de las reclamaciones territoriales españolas para inventar al Nuevo Mundo como un lugar aparte, pero esta vez se le llama América y se le concede el estatus de la cuarta parte del mundo. Este es un mapa para la nueva época que nació con los éxitos de Cortés y Pizarro y maduró con los fracasos de Coronado, Cabrillo y Villalobos, aquella nueva época en que se dejaba de imaginar que el Nuevo Mundo era una extensión del continente asiático o una enorme isla indiana, y se empezaba a creer de manera más general que era una enorme isla de estatus continental. Esta nueva época resultaba conveniente para la dinastía habsburga a finales de los años cincuenta. No sabemos casi nada de las circunstancias detrás de

34 Las únicas copias se encuentran en la Library of Congress en Washington, D.C. y la British Library en Londres. La Library of Congress ha digitalizado su copia en alta la producción de este mapa, aunque John Hébert supone que la negociación de la Paz de Cateau Cambrésis (1559) entre España, Francia e Inglaterra representa el momento clave en su fabricación, y que el mapa sirvió para reconocer la legitimidad de la presencia francesa en el noreste del continente americano. Nota que la línea de la demarcación en el Atlántico brilla por su ausencia (Hébert, n.d.). Esta omisión podría formar parte de la estrategia diplomática detrás del diseño. Aparecen las armas francesas al lado de las habsburgas, y se identifica a parte de Norteamérica como Tierra Francisca, pero no se dibuja una frontera específica entre aquel territorio francés y las partes de América controladas por España. De manera parecida, se incluyen las armas de Portugal en el Atlántico Sur, reconociendo de esta forma la legitimidad del poderío portugués en aquella zona, pero se omite la línea de la demarcación para no entrar en controversias sobre su ubicación específica entre la América portuguesa y la española. El recorte de la imagen original sirve para extender esta estrategia de silencio diplomático. Al dejar fuera el resto de las Indias españolas, irrelevantes de todos modos para las negociaciones con Francia e Inglaterra, se evitaba la representación de la frontera lusocastellana en Asia. De esta manera, el recorte de la imagen no solamente sirve para contribuir a la invención de América, sino también para apoyar la estrategia de silencio diplomático necesario para fomentar la paz internacional.

Al hacer todo esto, sin embargo, el mapa de Cocke y Gutiérrez abandona la visión española de las Indias como un espacio abarcador. Al respetar el agnosticismo de su fuente frente a la posible insularidad del continente americano, el mapa se abre a la posibilidad de que el Nuevo Mundo podía estar físicamente conectado a Asia, pero al excluir los territorios asiáticos que la cartografía manuscrita castellana seguía cartografiando como parte de la demarcación española, pierde la oportunidad de enmarcar aquel espacio incógnito como un imperio transmagallánico en construcción. A la vez que deja todo aquel espacio fuera del marco, también crea un contraste marcado entre la conquista del Mar del Norte y

resolución y la ha hecho disponible en la red. Véase https:// www.loc.gov/resource/g3290.ct000342. Acceso el 13 de julio del 2019. 
las frustraciones representadas por el Mar del Sur. En el Atlántico predominan imágenes de triunfo marítimo y de actividad productiva, como son la figura alegórica de un rey que cruza el Atlántico en el carro de Neptuno, tirado por cuatro hipocampos, y la imagen de una flota portuguesa en camino a las Indias Orientales, pero más allá del estrecho de Magallanes predominan imágenes de desastre. De los seis barcos que navegan el Mar del Sur, tres se encuentran amenazados por animales marítimos o figuras mitológicas, uno está casi totalmente hundido y otro parece estar encalmado. Solamente uno navega sin problemas, pero rumbo a México, no a las Molucas. No se encuentra por ninguna parte a aquel Magallanes triunfante que usaba Vopel para figurar aquella cuenca oceánica como un lago español en construcción. Esta serie de desastres marítimos sirve para conmemorar los naufragios de las expediciones de Loaysa y Saavedra, y el problema persistente del tornaviaje, o sea, la ruta de regreso desde Asia al Nuevo Mundo. Queda plasmada la actitud de San Francisco Xavier, quien después de atender a los supervivientes del fiasco de Villalobos insistía en que el emperador debía abandonar sus ambiciones en el Mar del Sur porque cualquier barco que se enviara a navegar por sus aguas se perdería ${ }^{35}$. El contraste entre los dos océanos queda claro. Mientras la cultura europea había conquistado el Mar del Norte, permitiéndole proyectar poder sobre América, el Mar del Sur queda todavía indómito. Las posibilidades inspiradas por el descubrimiento del estrecho de Magallanes quedan del todo olvidadas.

\section{UN PASAJE AL LAGO ESPAÑOL}

De nuevo, una ironía. El mapa Gutiérrez/ Cocke habla de un mundo en el que América ha sido efectivamente inventada como un continente aparte y como el teatro por excelencia de la expansión transoceánica, mientras figura el Mar del Sur, pidiendo palabras prestadas de Denis Cosgrove, como el Ocean at the world's edge, accessed through the Straits of Magellan, the new Pillars of Hercules, o sea, un relieve del viejo Mar Océano que desafiaba las vanas pretensiones del ser humano al dominio del elemento acuático ${ }^{36}$. Mientras el mapa de Ramusio descarta la idea de que las Islas Molucas podrían formar parte de las Indias Occidentales, el mapa Gutiérrez/ Cocke se burla de la misma posibilidad de un imperio transmagallánico. Cuatro años después, sin embargo, España dispondría de una colonia incipiente en las islas Filipinas y dentro de poco operaría la primera ruta comercial transpacífica construida por europeos. La plata de América empezaría a viajar a China a través de Manila, y las sedas chinas llegarían a decorar las casas, las iglesias y los cuerpos de la América española. El viejo sueño de un imperio transmagallánico volvería a nacer de las cenizas, y se hablaría de una nueva etapa de conquistas espectaculares que rivalizarian con las de Cortés y Pizarro. No es mi propósito en esta sección recapitular la historia de esta transformación, sino comentar algunos aspectos del impacto que tuvo sobre el imaginario geopolítico español y el lugar del estrecho de Magallanes en ello ${ }^{37}$.

Ya para cuando se establece la colonia española en Filipinas durante la década de los sesenta queda olvidado el viejo plan de proyectar poder sobre el sudeste asiático desde España a través del estrecho de Magallanes. Esto fue lo que se había intentado en 1525, cuando se fundó una Casa de la especiería en La Coruña, y se despachó a la expedición de Loaysa hacia las Molucas por el camino del Estrecho, pero mientras la flota navegaba por el Pacífico, Oviedo insistía en que el largo desvío hacia el Sur implicado en la ruta

35 Xavier, 1996. Epistolae S. Francisci Xaverii aliaque eius scripta (Vols. 1-2). J. Wicki y G. Schurhammer, Eds. Recuperado de http://hdl.handle.net/2027/ mdp.39015050756850, pp. 2 y 356-357.

36 Cosgrove, 2001. Apollo's Eye: A Cartographic Genealogy of the Earth in the Western Imagination. Johns Hopkins University Press, Baltimore and London, p. 95.

37 La obra fundamental sobre el Pacífico español sigue siendo Spate, 1979, op. cit., aunque su texto se debe de leer,

como mínimo, a la luz de Frank, 1998. Reorient: Global Economy in the Asian Age. University of California Press, Berkeley; Flynn y Giráldez, 2010. China and the Birth of Globalization in the 16th Century. Ashgate Variorum, Farnham; y Gruzinski, 2014. The Eagle and the Dragon: Globalization and European Dreams of Conquest in China and America in the Sixteenth Century. Traducido por J. Birrell, Polity Press Cambridge, UK. 
magallánica la hacía impracticable y en que sería mejor organizar el trato de la especiería desde Panamá ${ }^{38}$. Aunque el fracaso de la expedición mostró que Oviedo tenía razón, todavía se hicieron otros intentos para utilizar el Estrecho como entrada al Mar del Sur, y hasta se llevó a cabo un reconocimiento detallado de su hidrografía entre 1558 y 1559. A pesar de estos esfuerzos, el centro de gravedad del colonialismo transpacífico efectivamente pasó a la Nueva España. La colonia en las islas Filipinas se comunicaría con el resto de la monarquía a través del puerto mexicano de Acapulco, y sería gobernada desde la Ciudad de México como parte del virreinato de la Nueva España. El estrecho de Magallanes caería en el olvido, y en 1569, el poeta Alonso de Ercilla le figuró como un lugar perdido al conocimiento español:

\section{Por falta de pilotos, o encubierta causa, quizá importante y no sabida, esta secreta senda descubierta quedó para nosotros escondida; ora sea yerro de la altura cierta, ora que alguna isleta, removida del tempestuoso mar y viento airado encallando la boca, la ha cerrado ${ }^{39}$.}

Todo esto cambia en 1577, cuando el corsario inglés Francis Drake logra utilizar la ruta por el Estrecho para penetrar en el Mar del Sur y llevar a cabo una serie de asaltos contra los puertos de Chile y Perú. Alarmado por la repentina incursión del enemigo en aguas que habían sido exclusivamente españolas, el virrey del Perú, Francisco de Toledo, despacha al cosmógrafo, soldado, historiador, poeta, marinero, y anticuario, Pedro Sarmiento de Gamboa, a cartografiar el estrecho de Magallanes, tomar posesión del territorio y averiguar si los ingleses se habían asentado en la zona. Después de llevar a cabo un reconocimiento exhaustivo del área, Sarmiento sale para España para proponer al rey que se pueble y fortifique el estrecho de Magallanes. Recibe el

38 Fernández de Oviedo y Valdés, 1950. Sumario de la natural historia de las Indias. Edición de J. Miranda. Recuperado de http://historia.ucr. ac.cr/cmelendez/bitstream/123456789/573/1/ SumarioNaturalHistoriaIndias.pdf, p. 270. encargo real para ejecutar este proyecto y le dedica los próximos siete años de su vida. Aunque al final fracasa, Sarmiento deja un legado textual que acaba teniendo repercusiones en la historiografía oficial de la Corona, particularmente en la historia de las Molucas escrita por Bartolomé Leonardo de Argensola a instancias del presidente del Consejo de Indias. Para Sarmiento, el Estrecho era más que nada un lugar americano que había que defender para garantizar la seguridad del virreinato del Perú. Argensola transforma la narrativa de Sarmiento, convirtiendo al Estrecho en el principal punto de entrada a un mundo pacífico concebido como un verdadero lago español.

En su Relación y derrotero del viaje y descubrimiento del Estrecho de la Madre de Dios antes llamado de Magallanes, Sarmiento de Gamboa relata sus actividades desde su salida del puerto de El Callao en octubre de 1579 hasta que llegó a Cádiz en agosto de 1580 y describe en detalle la geografía litoral de la zona del estrecho de Magallanes. El texto está diseñado para facilitar la ubicación del pasaje marítimo, la navegación por sus aguas y la población y fortificación de su territorio. También sirve para ilustrar la visión geoestratégica tanto del virrey Toledo como de Sarmiento de Gamboa respecto al Estrecho. El texto empieza de esta manera:

Después que Don Francisco de Toledo, Virréi del Pirú, embió una Amada de dos Navios con mas de doscientos hombres tras el Corsario Francisco Draquez ... considerando lo mucho que importaba a la seguridad de todas las Indias desta Mar del Sur ... a así mesmo por la pública fama y temor de los Navíos Ingleses ... que quedaban atrás en las Costas de Chile y Arica ... y porque la común voz del pueblo era que Francisco había de volver por el Estrecho ... determinó embiar a descubrir el Estrecho de Magallanes, que por esta Mar del Sur se tenía quasi por imposible poderse descubrir ${ }^{40}$.

39 Ercilla, 1993. La Araucana. Cátedra, Madrid, Canto I. Estrofa 9.

40 Sarmiento de Gamboa, 2000. Viajes al Estrecho de Magallanes. Edición de J. Batista González. Dastin, Madrid, p. 31 . 
¿Qué quiere decir el texto por todas las Indias desta Mar del Sur? Propongo que se refiere más que nada a la costa pacífica del virreinato del Perú, quizás a la costa pacífica de toda la América española, pero no a la cuenca oceánica entera. Ni en el momento y lugar referidos, Lima en el año 1578, ni en el momento y lugar en que finaliza el relato, 1580 en la isla de San Jorge, se sabía que Drake nunca regresaría al estrecho de Magallanes, que pasaría el invierno en California y que luego cruzaría el océano Pacífico para comerciar en las Molucas antes de regresar a Inglaterra por la ruta del cabo de Buena Esperanza. Por eso este pasaje menciona la amenaza que los corsarios representan para los puertos de Chile y Arica, pero jamás menciona una posible amenaza a la colonia española en Filipinas. La visión geoestratégica que guía las actividades de Sarmiento, y que se manifiesta en estas primeras páginas de su relato, es exclusivamente americana y quizás hasta regional.

El resto del texto en su mayor parte es intensamente local. Cada pasaje cuenta un pequeño trecho del viaje de la flota, haciendo observaciones sobre el rumbo y la distancia atravesada, y sobre temas diversos como la flora y la fauna, la profundidad del agua, las condiciones meteorológicas, los peligros a la navegación, etc. Poco a poco se va construyendo una cartografía de la región entera, pero la voz narrativa nunca pausa para generalizar, sintetizar y describir. Solamente trata de árboles, nunca del bosque. Por cierto, nunca adopta una perspectiva que podríamos llamar geoestratégica, mucho menos global. Las excepciones a esta tendencia incluyen las citas de los textos utilizados en dos diferentes actos de posesión en territorio magallánico, donde la escala geográfica cambia de manera abrupta, para hacer referencia a la cartografía de la demarcación y las legalidades conectadas a ella. El primero de estos pasajes explica que gracias a la donación del papa Alejandro VI, España goza de autoridad sobre la mitad del Mundo, que son ciento $y$ ochenta grados de Longitud, y que el estrecho de Magallanes cae dentro de aquel territorio ${ }^{41}$. El segundo varía las fórmulas, haciendo referencia explícita a la línea de demarcación dibujada por el
Papa, pero con el mismo propósito, la de insistir que España es el único país autorizado a ejercer soberanía sobre la zona ${ }^{42}$. La escala global aparece solamente una vez más, casi al final del texto, cuando Sarmiento se encuentra en las islas Azores, y llega la flota portuguesa de la India con noticias de un intento por parte de los españoles en Filipinas de conquistar la isla de Borneo. Por primera y única vez en el texto entero se menciona a Manila en los Luzones y la vía de Nueva España, o sea, la ruta del galeón de Manila ${ }^{43}$.

Es de notar que Sarmiento solamente menciona las Filipinas y las ambiciones imperiales de España en el sudeste asiático cuando, una vez en el Atlántico, recibe noticias de ellas de informantes portugueses que están regresando del Estado da India a Lisboa. El capitán sabe que existe aquella colonia junto con una ruta transpacífica que la comunica con la América española, pero aquello no parece entrar en su concepción de las Indias desta Mar del Sur. Aunque las noticias de Filipinas pueden viajar a España a través del Pacífico y México, las islas son para Sarmiento, o por lo menos para el Sarmiento de este texto, un sitio oriental que queda más allá de las posesiones portuguesas en el océano Índico, al otro lado del mundo. No forman parte de su mundo americano. El mapamundi conceptual construido por el texto resulta parecerse a la gran mayoría de los mapas del mundo concretos producidos durante el siglo XVI. El océano Atlántico se encuentra en el centro, el Nuevo Mundo a la izquierda en el oeste, y el Viejo Mundo a la derecha en el oriente. El estrecho de Magallanes representa el punto de entrada a un Mar del Sur concebido no como una cuenca marítima marcada a ambos lados por América y Asia, sino como las aguas que bañan las costas occidentales del continente americano (Fig. 8). En este texto, obra del primer autor documentado por el CNDHE que usa el término América para referirse al Nuevo Mundo, no encontramos una visión transpacífica de las Indias Occidentales.

El texto de Sarmiento quedó inédito en su época, pero parece que se encontraba disponible entre los papeles del Consejo de Indias utilizados por Bartolomé Leonardo de Argensola para 


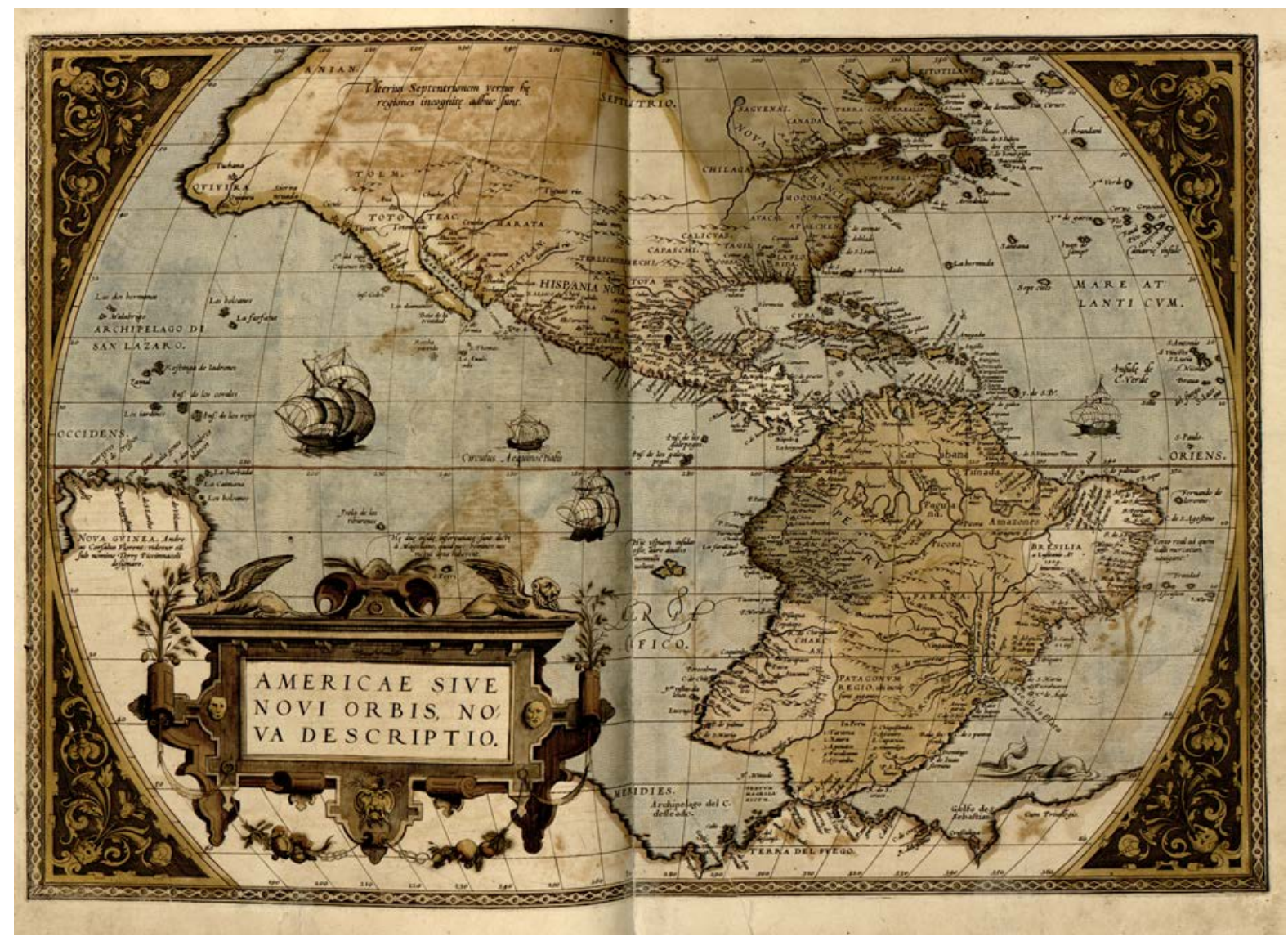

Fig. 8. El Mar del Sur como las aguas que bañan el Nuevo Mundo, no como cuenca marítima que une América a Asia. Abraham Ortelio. Americae sive novi orbis, nova descriptio (Amberes, 1570). Biblioteca del Congreso, Washington, D.C.

escribir su Conquista de las Islas Malucas (1609, 1992). El título se refiere al evento principal que celebra, la acción militar de Pedro Bravo de Acuña, el gobernador de Filipinas, contra los holandeses y sus aliados malayos en las islas de Tidore y Ternate, pero el texto abarca mucho más que la historia de esta campaña. Argensola relata toda la historia del encuentro ibérico con las islas de la Especiería desde la primera llegada de los portugueses a principios del siglo XVI, y lo relaciona con la contienda entre la Monarquía Hispánica y los poderes protestantes de Inglaterra y Holanda que marcaba su propia época. De esta manera, su historia de las Molucas adquiere una dimensión global, y la batalla por el control de aquéllas se convierte en un episodio de una guerra mundial. Para pasar de una escala a otra, Argensola aprovecha la visita de Drake a las Molucas para contar la historia de su circunnavegación y su persecución por Sarmiento de Gamboa, utilizando el relato del capitán español como fuente. Sigue a Drake alrededor del mundo, y a Sarmiento desde El Callao al estrecho de Magallanes y a España. De este modo, el enfoque narrativo del texto se ensancha dramáticamente, y las islas Molucas se convierten en un nexo estratégico de una red de rutas marítimas que abrazan el mundo entero.

También se encuentran en el meollo de un mundo marítimo exclusivamente habsburgo que abarca tanto el océano Índico como el Pacífico, ya que estamos en el período de la unión de las coronas (1580-1640). Este océano ya no es el Mar del Sur del mapa de Vopel, que funde los nuevos descubrimientos con noticias de Asia heredadas de la Edad Media dentro de un marco geográfico marcado por la influencia de la cosmografía ptolemaica. Para componer su historia, Argensola 
ha consultado toda una serie de fuentes modernas originalmente escritas en varios idiomas $y$ ha adoptado una visión geográfica actualizada. En las páginas de Argensola, el Nuevo Mundo es América, la cuarta parte, no una extensión de Asia ${ }^{44}$. Las Indias no abundan de maravillas dudosas, y el Pacífico no sirve como lienzo para fantasías geográficas. No se trata de hombres con cabezas de perro ni se imagina una Terra Australis esperando a ser conquistada. Tampoco se trata, sin embargo, del espacio de un mercantilismo incipiente, donde lo que más importa es el tráfico de productos y bienes de consumo tropicales. A pesar del protagonismo ejercido por las islas Molucas, productoras de algunas de las comodidades más codiciadas de la época, y a pesar de la atención que se dedica a las riquezas de los muchos lugares descritos, el tema principal de la Conquista de las Islas Malucas es la religión. Esta es una crónica empapada por la ideología oficial de la corona habsburga que justificaba el imperialismo como un medio para difundir el catolicismo.

La historia del reconocimiento del estrecho de Magallanes por Sarmiento sirve para marcar la importancia de este pasaje como puerta de entrada al imperio católico de los habsburgos en este Mar del Sur ampliado, pero para que funcione de esta manera, Argensola tiene que retorcer la visión geopolítica tan plenamente americanista del texto original. Esto lo hace intercalando cuidadosamente los dos relatos. Cuenta la historia de Drake desde su salida de Inglaterra en noviembre de 1577 hasta su llegada a las Molucas en el verano de 1579. En este momento interrumpe el hilo narrativo para opinar sobre las implicaciones desastrosas de la incursión:

Ha se de advertir que como en España y en las Indias creían con firme opinión que nadie había pasado el Estrecho de Magallanes después que ello descubrió, sino Fray García de Loaysa y una de las Naves que Don Gutierre de Vargas, Obispo de Plasencia, envió a la especería, pareció

44 Argensola, 1609. Conquista de las Islas Malucas. Madrid, p. 85; Argensola, 1992. Conquista de las Islas Malucas. Miraguano, Madrid, p. 69.

45 Ibidem, p. 108; p. 105.

46 Ibidem, p. 123; p. 117. caso increíble haber entrado Piratas en el Mar del Sur. Por el Estrecho a lo menos, y a las Islas de Ternate, y a todo aquel populoso archipiélago ${ }^{45}$.

El verdadero desastre, continúa el cronista, es que Drake ha abierto aquel mundo al Protestantismo, pero gracias a Dios, el virrey Don Francisco de Toledo ha tomado las medidas necesarias para cerrar el camino de la infección. Así se maneja la transición de la historia de Drake a la historia de Sarmiento en el Estrecho. No se menciona que en el momento de zarpar Sarmiento, no se sabía nada en Lima de la visita del corsario al sudeste asiático, no solamente porque las noticias todavía no habían llegado, sino porque el evento mismo aún no había ocurrido. En aquel momento, Drake se encontraba en el Pacífico Norte, cerca de California, y todavía no había cruzado el océano. Argensola, sin embargo, omite las fechas en esta parte de su relato, y de esa manera crea una relación falsa de causa y efecto entre las acciones de Drake en las Molucas y el plan virreinal para reconocer y fortificar el estrecho de Magallanes. Cuando Sarmiento deja una carta en la boca del Estrecho prohibiendo la entrada a todos los que no sean súbditos del rey de España, tenemos la impresión de que sus órdenes se refieren no solamente al Estrecho mismo o a las costas pacíficas del virreinato del Perú, sino a todas las Indias desta Mar del Sur, incluyendo a las Filipinas y las Molucas ${ }^{46}$.

Esta manera de contar la historia de Sarmiento refleja el pensamiento de la Corona en relación a la importancia del Estrecho en años posteriores a los eventos, no la visión geoestratégica de Toledo y Sarmiento en el momento ${ }^{47}$. Dentro de ese marco, las Indias desta Mar del Sur incluían todas las posesiones habsburgas en el Pacífico y el Índico, no solamente la costa pacífica de Sudamérica. Para mapear ese espacio en su totalidad Argensola relata la historia de uno de los primeros viajes holandeses a las islas de la Especiería, el de Jacob Corneliszoon van Neck (1598-1599). Traza la ruta de la flota

47 Para el desarrollo de aquel pensamiento, véase Sheehan, 2008. Iberian Asia: The Strategies of Spanish and Portuguese Empire Building, 1540-1700. (PhD. Dissertation). University of California, Berkeley, p. 291. 
holandesa desde su país a Ternate, pasando por la isla de Mauricio en el estrecho de Mozambique, donde los holandeses cuelgan un letrero que reza LOS CRISTIANOS REFORMADOS ${ }^{48}$. El gesto de los holandeses reclama el estrecho de Mozambique para Holanda, anuncia la penetración de las Indias por el Protestantismo y parodia el gesto de Sarmiento en el estrecho de Magallanes. Señala al lector que mientras se ha tomado medidas para asegurar la entrada al Mar del Sur por el este, la entrada al mismo espacio por el occidente ha caído en manos de enemigos. Hace falta otro Sarmiento para aquel otro estrecho homólogo al de Magallanes, para proteger a todo el Mar del Sur del contagio protestante.

\section{CONCLUSIÓN}

¿A dónde, en fin, nos lleva el estrecho de Magallanes? Dicho de otra manera, ¿cuál es el marco geográfico, político y más que nada, epistemológico, dentro del cual se debe entender aquel pasaje entre el Atlántico y el Pacífico? Al identificar al Estrecho como un sitio "americano" adoptamos una postura perfectamente válida y por cierto razonable, una postura adoptada por ciertos pensadores de la época en que se descubrió el Estrecho, y la postura que eventualmente llegó a triunfar, pero también descartamos las otras posibilidades propuestas por la cultura del siglo XVI, particularmente en el ámbito hispánico. Nos olvidamos de la otra ruta, tan geográfica como intelectual, mediante la cual el estrecho de Magallanes forma parte de una geografía más abarcadora, las Indias transpacíficas de la imaginación española. Aquella ruta jamás quedó descartada, aun en aquellos momentos que se han identificado como etapas decisivas en la invención de América como un continente aparte, como son la década de los veinte, de los cuarenta y de los setenta del siglo XVI. Por el contrario, esperamos haber mostrado que aquel proceso de invención se llevó a cabo dentro de un encuentro dialéctico con una serie de visiones alternativas que de alguna manera u otra mantenían al Nuevo Mundo unido

48 Argensola, 1609, op. cit., p. 237; 1992, p. 218. Patricia Seed ubica este evento en el contexto de las ceremonias de posesión holandesas. Seed, 1995. Ceremonies of con Asia. Encontramos, en fin, que la pregunta " ¿a dónde nos lleva el estrecho de Magallanes?" nunca tiene una respuesta definitiva, pues deberíamos tener en cuenta aquella parte del mapa que solemos olvidar cuando nos concentramos exclusivamente en la imagen de América.

\section{BIBLIOGRAFÍA}

Bourne, E. G. (1904). Spain in America, 1450-1580. Harper \& Brothers.

Buisseret, D., \& Holzheimer, A. (1992). The "Ramusio" Map of 1534: A Facsimile Edition. Chicago: Newberry Library.

Cosgrove, D. (2001). Apollo's Eye: A Cartographic Genealogy of the Earth in the Western Imagination. Baltimore and London: Johns Hopkins University Press.

Davies, S. (2003). The Navigational Iconography of Diogo Ribeiro's 1529 Vatican Planisphere. Imago Mundi: The International Journal for the History of Cartography, 55(1), pp. 103-112.

Davies, S. (2011). America and Amerindians in Sebastian Münster's "Cosmographiae universalis libri VI" (1550). Renaissance Studies, 25, 351-373.

Flint, R., \& Flint, S. C. (2013). No Settlement, No Conquest: A History of the Coronado Entrada. Albuquerque: University of New Mexico Press.

Flynn, D. O., \& Giráldez, A. (2010). China and the Birth of Globalization in the 16th Century. Farnham: Ashgate Variorum.

Frank, A. G. (1998). Reorient: Global Economy in the Asian Age. Berkeley: University of California Press.

Gruzinski, S. (2014). The Eagle and the Dragon: Globalization and European Dreams of Conquest in China and America in the Sixteenth Century. Traducido por J. Birrell.. Cambridge, UK: Polity Press.

Hébert, J. R. (n.d.). The 1562 Map of America by Diego Gutiérrez. Recuperado el 14 de Julio del 2014 https:// www.loc.gov/rr/hispanic/frontiers/gutierrz.html

Horodowich, E. (2018). The Venetian Discovery of America: Geographic Imagination in the Age of Encounters. Cambridge and New York: Cambridge University Press.

Horodowich, E., \& Nagel, A. (2019). Amerasia: European Reflections of an Emergent World, 1492-ca. 1700. Journal of Early Modern History, 23, 257-295.

Possession: Europe's Conquest of the New World, 1492 1640. Cambridge University Press, Cambridge, pp. 165167. 
Kelsey, H. (1998). Juan Rodríguez Cabrillo. San Marino, CA: Huntington Library.

Kunstmann, F. (1859). Atlas zur Entdeckungsgeschichte Amerikas. Munich: Asher in Comm.

León-Portilla, M. (2005). Hernán Cortés y la Mar del Sur. Madrid: Algaba.

Lois, C. (2018). Terrae incognitae: Modos de pensar y mapear geografías desconocidas. Buenos Aires: Editorial Universitaria de Buenos Aires.

Martín-Merás, L. (1992). Cartografía marítima hispánica: La imagen de América. Madrid: Lunwerg.

Morales Padrón, F. (1963). Historia del Descubrimiento y Conquista de América. Madrid: Editorial Nacional.

Morison, S. E. (1971). The European Discovery of America. New York: Oxford University Press.

Onetto, M. (2017). Modernidad, historicidad y construcción de territorialidades desde un pasaje-mundo. El estrecho de Magallanes tras su "Descubrimiento". Magallania, 45(2), 37-58.

Padrón, R. (2016). (Un)Inventing America: The Transpacific Indies in Oviedo and Gómara. Colonial Latin American Review, 25(1), 16-34.

Padrón, R. (2020). The Indies of the Setting Sun: How Early Modern Spain Mapped the Far East as the Transpacific West. Chicago: University of Chicago Press.

Parry, J. H. (1974). The Discovery of the Sea. New York: The Dial Press.

Randles, W. G. L. (2000). Classical Models of World Geography and Their Transformation Following the Discovery of America. En Geography, Cartography and Nautical Science in the Renaissance: The Impact of the Great Discoveries (pp. 5-76). Aldershot, Hampshire, Great Britain; Burlington, Vt., USA: Ashgate/Variorum.

Safier, N. (2014). The Tenacious Travels of the Torrid Zone and the Global Dimensions of Geographical Knowledge in the Eighteenth Century. Journal of Early Modern History, 18(1-2), 141-172.

Sánchez, A. (2013). La espada, la cruz y el Padrón: Soberanía, fe y representación cartográfica en el mundo ibérico bajo la Monarquía Hispánica, 1503-1598. Madrid: Consejo Superior de Investigaciones Científicas.

Seed, P. (1995). Ceremonies of Possession: Europe's Conquest of the New World, 1492-1640. Cambridge: Cambridge University Press.

Sheehan, K. J. (2008). Iberian Asia: The Strategies of Spanish and Portuguese Empire Building, 1540-1700 (PhD. Dissertation). University of California, Berkeley.

Spate, O. H. K. (1979). The Spanish Lake. Minneapolis:
University of Minnesota Press

Steinberg, P. E. (2001). The Social Construction of the Ocean. New York and London: Cambridge University Press.

Stevenson, E. L. (1921). Terrestrial and Celestial Globes: Their History and Construction. New Haven: Yale University Press for the Hispanic Society of America.

Suárez, T. (2004). Early Mapping of the Pacific: The Epic Story of Seafarers, Adventurers, and Cartographers who Mapped the Earth's Greatest Ocean. Singapore: Periplus.

Wey Gómez, N. (2008). The Tropics of Empire: Why Columbus Sailed South to the Indies. Cambridge, Mass.: MIT Press.

Wey Gómez, N. (2013). Memorias de la zona tórrida: El naturalismo clásico y la "tropicalidad" americana en el Sumario de la natural historia de las Indias de Gonzalo Fernández de Oviedo (1526). Revista de Indias, 73(259), 609-632.

Wroth, L. C. (1944). The Early Cartography of the Pacific. The Bibliographical Society of America, Papers, 38, 87268.

\section{FUENTES}

Albo, F. (1837). Diario o derrotero del viage de Magallanes dese el cabo de San Agustín en el Brasil, hasta el regreso a España de la nao Victoria. En Fernández de Navarrete (Ed.), (1765-1844). Coleccion de los viages y descubrimientos que hicieron por mar los españoles desde fines del siglo XV: con varios documentos inéditos concernientes a la historia de la Marina Castellana y de los establecimientos españoles en Indias (pp. 209-247). Madrid: Imprenta Real.

Anghiera, P. M. d. (1530). De orbe nouo Petri Martyris ab Angleria Mediolanensis Protonotarij Cesaris senatoris decades. Compluti: Apud Michael*e d'Eguia.

Anghiera, P. M. d'. (1534). Libro primo della historia del' Indie Occidentali. Venice: Stefano Nicolini da Sabbio.

Anglería, P. M. de. (1989). Décadas del Nuevo Mundo. Madrid: Ediciones Polifemo.

Argensola, B. L. de. (1609). Conquista de las Islas Malucas. Madrid.

Argensola, B. L. de. (1992). Conquista de las Islas Malucas. Madrid: Miraguano.

Cortés, H. (1522). Carta de relacio[n] elm]biada a Su. S. Majestad del e[m]p[er]ador n[uest]ro señor. Retrieved from http://ncco.tu.galegroup.com/tinyurl/RNR6

Cortés, H. (1524). Praeclara Ferdinandi Cortesii De Noua Maris Oceani Hyspania Narratio ... Carolo 
Romanor-u Imperatori ... M.D.XX Transmissa ... Per Petr-u Saguorgnan $u$ [sic] Ex Hyspano Idiomate in Latin`u Versa Anno Dn־i, M.D.XXIIII Kl. Martii. [Explicit Secunda Ferdinandi Cortesii Narratio. Nuremburg.

Ercilla, A. de. (1993). La Araucana. Madrid: Cátedra.

Fernández de Oviedo, G. (1535). La historia general de las Indias. Recuperado de http://hdl.handle.net/2027/ ucm. 5323537519

Fernández de Oviedo y Valdés, G. (1851). Historia general y natural de las Indias. J. Amador de los Ríos (Ed.). Madrid: Imprenta de la Real Academia de la Historia. Google Books.

Fernández de Oviedo y Valdés, G. (1950). Sumario de la natural historia de las Indias J. Miranda (Ed.). Recuperado de http://historia.ucr.ac.cr/ cmelendez/bitstream/123456789/573/1/ SumarioNaturalHistorialndias.pdf

Las Casas, B. de. (1986). Historia de las Indias (Vols. 1-3; A. Saint-Lu, Ed.). Caracas, Venezuela: Biblioteca Ayacucho.

López de Gómara, F. (1552). La Historia de las Indias y Conquista de Mexico. Zaragoza: Agustín Millán.

López de Gómara, F. (1979). Historia general de las Indias y Vida de Hernán Cortés. J. Gurría Lacroix (Ed.). Caracas, Venezuela: Biblioteca Ayacucho.

López de Gómara, F. (2007). Historia de la conquista de México. J. Gurría Lacroix (Ed.). Recuperado de http://archive.org/details/GomaraFranciscoLopezDe.
HistoriaDeLaConquistaDeMexico2007

Pigafetta, A. (1525). Le voyage et nauigation, faict par les Espaignolz es Isles de Mollucques. Des isles quilz ont trouue audict voyage, des roys dicelles, de leur gouuernement \& maniere de viure, auec plusiers aultres. On les vend a Paris: en la maison de Simon de Colines libraire iure de luniuersite de Paris demoura[n]t en la rue Sainct Jehan de Beauluais a lenseigne du Soleil Dor.

Pigafetta, A. (1969). The Voyage of Magellan: The Journal of Antonio Pigafetta. A Translation by Paula Spurlin Paige from the Edition in the William L. Clements Library, University of Michigan, Ann Arbor. Transcripción de P. S. Paige. Englewood Cliffs, NJ: Prentice-Hall.

Pigafetta, A., \& Transylvanus, M. (1969). First Voyage Around the World. C. Quirino (Ed.). Manila: Filipiniana Book Guild.

Sarmiento de Gamboa, P. (2000). Viajes al Estrecho de Magallanes. J. Batista González (Ed.). Madrid: Dastin.

Transylvanus, M. . (1523, anno uirginei partus. MDXXIII. [ ] mense Ianuario). De Moluccis insulis, itemq[ue];: Alijs pluribus mira[n]dis, quae nouissima Castellanorum nauigatio Sereniss. Recuperado de http://search.lib. virginia.edu/catalog/uva-lib:2505639

Xavier, F. (1996). Epistolae S. Francisci Xaverii aliaque eius scripta (Vols. 1-2; J. Wicki \& G. Schurhammer, Eds.). Recuperado de http://hdl.handle.net/2027/ mdp.39015050756850 